INRA Prod. Anim.

2013, 26 (4), 347-362

\title{
La (méta)génomique des microorganismes du rumen et ses applications à la production des ruminants
}

\author{
D.P. MORGAVI I, , W.J. KELLY', P.H. JANSSEN ${ }^{3}$, G.T. ATTWOOD \\ 1 INRA, UMR1213 Herbivores, F-63122 Saint-Genès-Champanelle, France \\ 2 Clermont Université, VetAgro Sup, UMR1213 Herbivores, BP 10448, F-63000 Clermont-Ferrand, France \\ ${ }^{3}$ Nutrition and Animal Health, AgResearch, Private Bag 11008, Palmerston North 4442, New Zealand
}

Courriel : diego.morgavi@clermont.inra.fr

Les microorganismes du rumen permettent aux ruminants de transformer les plantes fourragères, non comestibles pour les humains, en aliments de haute qualité. Cependant, ils sont également responsables de la production de méthane. La génomique et la métagénomique sont en train de révolutionner notre compréhension des fonctions des écosystèmes digestifs et des interactions entre les microorganismes et l'animal hôte' ${ }^{1}$.

Le terme « super-organisme » est utilisé pour décrire le lien étroit existant entre un animal hôte et son microbiome symbiotique (Lederberg 2000, Goodacre 2007). Le microbiome gastro-intestinal (cf. encadré) exerce des fonctions protectrices, immunologiques, de développement et nutritionnelles qui sont bénéfiques à l'hôte (Hooper 2004). Il peut être considéré à juste titre comme un « organe » possédant bien plus de fonctions et de capacités métaboliques que les tissus de l'hôte (Xu et Gordon 2003, Egert et al 2006, Gill et al 2006). Chez l'Homme, il a été démontré qu'il existe au moins 3,3 millions de gènes microbiens non redondants, un chiffre 150 fois supérieur au nombre de gènes présents dans le génome humain (Qin et al 2010). Chez les herbivores domestiques, en particulier chez les ruminants, l'importance des microorganismes gastro-intestinaux symbiotiques au niveau de la nutrition, de la santé et du bien-être de l'hôte a été reconnue bien avant qu'un bénéfice équivalent ait été observé chez l'Homme. Les ruminants prélèvent de l'énergie dans des polyosides structurels des plantes, autrement indigestibles, en offrant un environnement adéquat aux microorganismes symbiotiques du tractus gastrointestinal. Cet environnement est régulé de sorte que les microorganismes fermentent les aliments et que l'hôte ruminant puisse absorber les produits terminaux de la fermentation pour se nourrir. L'hôte bénéficie également des métabolites microbiens, tels que les vitamines et des protéines de haute qualité contenues dans les microorganismes, pour ses besoins nutritionnels. D'un point de vue microbiologique, la domestication des ruminants est un usage réussi des microorganismes par les humains (Russell et al 2009).

Les effectifs mondiaux de ruminants domestiques sont de 1,38 milliards pour les bovins, 1,96 milliards pour les ovins et caprins et 0,22 milliard pour les buffles et les camélidés (FAO 2009). Ils constituent les moyens de subsistance directs ou indirects de millions de personnes dans le monde. La valeur économique des produits issus des ruminants est aussi importante pour les pays en développement que pour les pays développés. La viande et/ou le lait issus des ruminants sont classés en tête des aliments et denrées agricoles les plus importants produits dans tous les continents, sauf en Asie, où le riz est en première place (FAO 2009). En raison de la croissance de la population humaine et de l'augmentation de la consommation de nourriture, on prévoit que la demande en viande et en lait soit multipliée par deux dans les 40 prochaines années (FAO 2006), augmentant ainsi inévitablement le nombre de ruminants dans le monde, ce qui représentera un défi pour les ressources globales et la sécurité alimentaire (World Bank 2008). Les symbiotes microbiens du rumen donnent aux ruminants la capacité de s'alimenter de fourrages et autres aliments impropres à la consommation humaine, permettant ainsi l'usage de terres agricoles ne convenant pas aux cultures, en particulier les céréales qui peuvent être consommées directement par les humains. Toutefois, ces mêmes ruminants sont également responsables de la production de méthane, gaz à fort effet de serre issu des fermentations microbiennes, ainsi que d'autres polluants tels que les excréments riches en azote. Ainsi, le microbiome du rumen représente à la fois un avantage majeur pour la production de produits animaux à partir des ruminants, mais aussi une source de rejets polluants dans l'environnement.

Il existe peu d'études alliant la microbiologie du rumen à des recherches sur la nutrition des ruminants. Il est vrai que la connaissance des microorganismes du rumen n'est pas strictement nécessaire pour alimenter ou élever des ruminants. Cependant, une compréhension approfondie des fonctions du microbiome gastro-intestinal et de son interaction avec l'animal hôte faciliterait la production de viande et de lait de façon plus durable et écologiquement viable. La richesse d'informations sans précédent que l'on peut obtenir en utilisant des méthodes « omiques » (technologies de séquençage génomique et métagénomique de deuxième génération, métatranscriptomique et méta-métabolomique) pour caractériser l'écosystème microbien digestif, associée aux génomes séquencés des bovins et des ovins (The Bovine

\footnotetext{
${ }^{1}$ Ce texte est adapté d'une publication parue en langue anglaise dans la revue Animal (Morgavi et al 2013).
} 
Genome Sequencing Analysis Consortium et al 2009, The International Sheep Genomics Consortium et al 2010), permet de considérer le super-organisme des ruminants comme un système intégral. Ceci devrait permettre de nouvelles avancées sur des questions importantes liées à la production animale, telles que l'efficacité de la digestion des fourrages et les émissions de méthane des ruminants.

Cet article a pour but de résumer les progrès récents de la génomique et de la métagénomique (cf. encadré) microbienne appliquées au tractus gastrointestinal des animaux d'élevage, en particulier le rumen, et d'identifier les données qui sont encore nécessaires pour mieux comprendre son fonctionnement et sa productivité.

\section{1 / Le ruminant, un « super- organisme »}

Le « super-organisme » ruminant est un système complexe et interdépendant constitué de plusieurs parties. L'hôte et son microbiome sont deux composantes majeures qui ont co-évolué pendant des millions d'années, s'assurant une adéquation accrue et de plus grandes chances de survie mutuelle. La composition des aliments est un autre facteur qui influence profondément le fonctionnement du microbiome et la physiologie de l'hôte (Ley et al 2008a, Clauss et al 2011). Le régime herbivore est une stratégie efficace qui a permis aux mammifères d'élargir l'étendue de leur habitat. Chez les mammifères, la diversification des lignées d'herbivores modernes - les ancêtres de notre bétail - a augmenté de façon notable avec l'apparition des graminées, il a près de 25 millions d'années (Hume et Warner 1980). Par conséquent, les espèces herbivores sont prédominantes parmi le nombre total de mammifères existants et sont parmi les plus grandes espèces sur terre (Stevens et Hume 1998). Dans la catégorie des herbivores, le tractus gastro-intestinal des ruminants s'est développé et le temps de rétention des fourrages a augmenté afin de faciliter la fermentation des aliments par les microorganismes symbiotiques. Les ruminants ont développé un système très sophistiqué pour abriter et profiter des microorganismes présents dans l'estomac (Stevens et Hume 1998, Clauss et al 2010), ce qui leur permet de s'adapter à une grande variété de régimes alimentaires. Cette caractéristique fut certainement un aspect important de la domestication (Diamond 2002) et elle peut être attribuée directement aux microorganismes. La stratification du contenu du rumen en couches de gaz, de solides et de liquides permet la rétention de particules

Encadré. Définitions.

Microbiome du rumen : ensemble des microbes, de leurs éléments génétiques (génome) et de leur interactions environnementales dans le rumen.

Metagénomique : étude du matériel génétique d'un écosystème complet tel que le rumen réalisé par séquençage collectif de l'ensemble de microbes.

Métatranscriptomique : étude de l'ensemble des ARN messagers exprimés par un écosystème complet tel que le rumen.

d'aliments qui seront traitées ultérieurement, tout en permettant la collecte des protéines microbiennes grâce au renouvellement des liquides (Clauss et al 2010). Les ruminants ont aussi une forte immunité innée au niveau des surfaces digestives intestinales et produisent des enzymes telles que le lysozyme et la ribonucléase qui participent à la dégradation des composés microbiens (Benner et al 2002, The Bovine Genome Sequencing Analysis Consortium et al 2009). Ces caractéristiques adaptatives ont évolué à la fois pour tolérer et utiliser les produits de l'« organe microbien ».

\section{1 / Les microorganismes gastro- intestinaux : qui sont-ils et quelle est leur fonction?}

$\mathrm{Si}$, d'un point de vue nutritionnel, le microbiome est considéré comme un composant unique, ses fonctions métaboliques lui sont attribuées par ses différents membres microbiens individuels.

Le rumen est un écosystème complexe qui abrite des centaines de phylotypes de bactéries, de protozoaires, de champignons, d'archées et de bactériophages. Ces organismes interagissent les uns avec les autres et avec leur environnement, à savoir l'hôte et ses aliments, comme indiqué plus haut. Leur concentration (jusqu'à $10^{11}, 10^{6}, 10^{6}, 10^{9}$, et $10^{10}$ cellules ou particules/mL respectivement pour les bactéries, les protozoaires, les champignons, les méthanogènes et les bactériophages) et leur activité hydrolytique sont exceptionnellement élevées par rapport à celles rencontrées dans les écosystèmes terrestres et aquatiques (Williams et Coleman 1992, Hobson et Stewart 1997, Mackie et al 2002 , Weimer et al 2009). Comme pour d'autres écosystèmes, le nombre d'espèces microbiennes isolées et caractérisées provenant du rumen est faible. On estime que moins de $15 \%$ des bactéries du rumen peuvent être cultivées en utilisant des techniques standards (Teather 2001, Edwards et al 2004), soulignant ainsi l'importance des approches de la biologie moléculaire dans le but de contourner cette limitation et d'étudier le système du rumen dans sa totalité. L'importance des approches de la biologie moléculaire est encore plus évidente lorsque l'on tient également compte de la variation intrinsèque d'un animal à l'autre. Afin d'obtenir des études approfondies permettant de découvrir les orientations, il peut être nécessaire d'analyser un grand nombre d'échantillons à la fois.

\section{2 / Est-il nécessaire de carac- tériser complètement le micro- biome?}

Quels avantages la caractérisation du microbiome du rumen apportera-t-elle à la production des ruminants? Les fonctions de base du microbiome du rumen en rapport avec la nutrition et la santé des ruminants, telles que la dégradation des aliments, la détoxification des toxines végétales et des contaminants alimentaires, la biotransformation des molécules présentant un intérêt nutritionnel pour les humains ou la production de méthane, ont été décrites (Hobson et Stewart 1997). De même, certaines pratiques alimentaires ou la distribution de suppléments et additifs qui régulent le microbiome du rumen pour améliorer la digestion des aliments et/ou diminuer les processus inefficaces sont reconnues et appliquées en pratique (Nagaraja et al 1997, Jouany et Morgavi 2007, Chaucheyras-Durand et al 2008, Martin et al 2010). Cependant, malgré les quantités d'informations accumulées, la compréhension du fonctionnement et de l'écologie du microbiome du rumen, qui permettrait de prédire son comportement, reste incomplète. Par exemple, l'ensemble du mécanisme de la dégradation des polyosides végétaux, la fonction caractéristique du rumen, n'est toujours pas élucidé (Morrison et al 2009, Wilson 2011). La plupart des travaux portant sur la dégradation des fibres dans le rumen est fondée sur l'étude de trois bactéries cultivables : Fibrobacter succinogenes, Ruminococcus albus et Ruminococcus flavefaciens. Parce qu'elles sont capables d'hydrolyser la cellulose cristalline, elles ont été considérées comme importantes dans le rumen (Flint et al 2008, Wallace 2008, Russell et al 2009). Les génomes de ces trois bactéries ont été séquencés (voir \$3.1) et les stratégies enzymatiques de dégradation de la cellulose utilisées par chaque espèce ont été élucidées. Il existe également des informations concernant d'autres bactéries du rumen capables d'attaquer 
des polyosides végétaux structurels telles que Prevotella et Butyrivibrio (Kelly et al 2010, Purushe et al 2010), ainsi que certains protozoaires (Bera-Maillet et al 2005) et les champignons anaérobies (Griffith et al 2010). Cependant, la communauté microbienne qui réalise la déconstruction complexe des parois cellulaires végétales et la façon dont les composantes de la communauté interagissent ne peuvent être entièrement décrites pour le moment. On a constaté que les bactéries $F$. succinogenes, $R$. flavefaciens et $R$. albus représentent seulement 1 à $3 \%$ des bactéries totales présentes dans le rumen (Stevenson et Weimer 2007, Mosoni et al 2011). Les substrats utilisés pour la quantification pourraient être trop spécifiques pour détecter tous les membres de ces genres (Russell et al 2009), mais des données récentes suggèrent également que les microorganismes attachés aux substrats végétaux appartiennent en grande partie à des bactéries phylogénétiquement distinctes de ces trois espèces (Brulc et al 2009, Hess et al 2011).

Un autre domaine exclusivement lié à l'activité du microbiome, et pour lequel nous manquons encore d'informations, est la production de méthane entérique. Le méthane est produit par un groupe spécialisé de microorganismes, les archées méthanogènes (Liu et Whitman 2008). La fonction métabolique de ce groupe est connue, la communauté méthanogène présente une diversité limitée par rapport à celle des bactéries et son niveau de population peut être estimé correctement à différents endroits du rumen et suivi dans le temps (Janssen et Kirs 2008). En outre, le génome de Methanobrevibacter ruminantium, une espèce méthanogène omniprésente dans le rumen, est disponible (Leahy et al 2010) et le séquençage des génomes d'autres méthanogènes du rumen est en cours (voir § 3.2). Cependant, en dépit de toutes ces informations, la méthanogénèse dans le rumen ne peut être corrélée au nombre de bactéries méthanogènes (Yanez-Ruiz et al 2008, Mosoni et al 2011, Popova et al 2011), ni explicitement attribuée à une structure communautaire particulière (Zhou et al 2010, Morgavi et al 2012). La production de méthane est intimement liée à la concentration d'hydrogène et aux interactions des bactéries méthanogènes avec d'autres microorganismes produisant et consommant de l'hydrogène dans le rumen (Janssen 2010, Morgavi et al 2010).

La compréhension incomplète des contrôles microbiologiques de la dégradation des fibres végétales et de la production de méthane souligne l'importance d'une approche intégrée pour comprendre le fonctionnement de la communauté et évaluer l'importance de ses membres pour la productivité du rumen et de l'animal hôte. L'application des technologies de séquençage de deuxième et troisième génération et le futur lancement de technologies de séquençage de quatrième génération avec une réduction constante des coûts, des lectures plus longues et des résultats plus rapides (Perkel 2011) permettent d'explorer la complexité du microbiome du rumen en utilisant une approche de biologie des systèmes (Raes et Bork 2008). Ces derniers ont affirmé qu'une telle approche exige un catalogue complet des espèces et en particulier des gènes présents dans le système, ainsi qu'une compréhension de la façon dont ces espèces/gènes interagissent et varient dans le temps comme dans l'espace. Dans les parties suivantes, nous allons résumer les principales informations disponibles sur l'écosystème du rumen et préciser les domaines où il est nécessaire d'obtenir plus de données pour combler les lacunes.

\section{2 / La diversité microbienne du rumen}

L'évolution de l'étude de la diversité microbienne du rumen est semblable à celle des autres écosystèmes microbiens, elle a commencé par des observations microscopiques basées sur la culture, puis a évolué vers le recours à des techniques moléculaires indépendantes de la culture.

\section{1 / Les empreintes moléculaires}

Le gène de la petite sous-unité de l'ARN ribosomique (rrs) est la cible la plus couramment utilisée pour caractériser cette diversité. Pour les archées méthanogènes, le gène codant la méthylecoenzyme $M$ réductase (mcrA) de la voie de la méthanogénèse est également un marqueur phylogénétique (Luton et al 2002) qui a été utilisé dans les études du rumen (Denman et al 2007). Récemment, la diversité des archées méthanogènes du rumen a été étudiée en utilisant le gène codant les protéines chaperonnes de type II (Chaban et Hill 2011). Des gènes moins universellement distribués, indicatifs de certaines fonctions, ont également été utilisés pour étudier certaines parties de la communauté microbienne. Par exemple, les gènes codant la formyltétrahydrofolate synthétase $(f h s)$ et l'acyl-CoA synthétase (acsB) ont été utilisés pour identifier des espèces potentiellement homo-acétogènes dans le rumen (Gagen et al 2010, Henderson et al 2010).

La quantification d'espèces microbiennes spécifiques en utilisant l'amplification par PCR du rrs génère des informations sur la présence et la densité des microorganismes cibles dans le rumen. Les variations temporelles et spatiales dans le nombre des copies rrs induites par des conditions différentes peuvent ensuite être associées à des paramètres biochimiques et fonctionnels de l'écosystème. Cette approche peut fournir des informations utiles à l'évaluation de l'effet des traitements alimentaires sur le microbiome du rumen, par exemple, les changements liés à des régimes acidogènes chez les vaches laitières (Khafipour et al 2009). Cependant, les espèces pour lesquelles des amorces de PCR spécifiques sont disponibles sont généralement celles qui peuvent être cultivées et il ne s'agit pas nécessairement des plus abondantes. En effet, il a été démontré que la plupart des espèces bactériennes du rumen auparavant jugées importantes ne représentent qu'une faible proportion de la communauté bactérienne totale (Stevenson et Weimer 2007). De plus, il n'existe aucune preuve du lien entre la capacité de cultiver une certaine espèce et son importance fonctionnelle dans l'écosystème. Les exigences de croissance des microorganismes et leur capacité à s'adapter aux conditions de culture en laboratoire sont les caractéristiques intrinsèques qui définissent la possibilité de l'isolement in vitro. Récemment, l'application de méthodes simples a permis de cultiver des microorganismes du rumen qui n'avaient pas été isolés auparavant (Kenters et al 2010, Koike et al 2010), laissant ainsi penser que l'approche de la culture pure est toujours utile pour comprendre les propriétés des taxons individuels. En particulier, les expérimentations contrôlées visant à tester les hypothèses concernant la fonction des gènes et la réponse microbienne à des stimuli est largement simplifiée lorsque les cultures sont disponibles. Les recherches basées sur la culture sont toujours valides et peuvent être complémentaires des approches de biologie moléculaire permettant d'étudier la structure et la fonction des communautés complexes.

L'utilisation des techniques d'empreintes moléculaires, dont les plus communément utilisées pour le rumen sont le polymorphisme de conformation des simples brins (SSCP) (Michelland et al 2009), l'électrophorèse sur gel à gradient dénaturant (DGGE) (Kittelmann et Janssen 2011, Popova et al 2011), le polymorphisme de longueur des fragments de restriction (RFLP) et sa variante terminal-RFLP (t-RFLP) (Khafipour et al 2009, Yáñez-Ruiz et al 2010), ainsi que l'analyse automatique de l'espace intergénique ribosomal (ARISA) (Sundset et al 2009, Welkie et al 2010) peuvent fournir de plus amples informations sur la structure du microbiome du rumen. Ces méthodes utilisent une approche non ciblée et sont capables de relever 
les différences et les similitudes dans la communauté de divers groupes microbiens présents dans le rumen, associés à l'espèce ruminante hôte, au régime alimentaire et à la conversion alimentaire (Larue et al 2005, Sadet et al 2007, Guan et al 2008, Suen et al 2011), mais elles ne fournissent pas d'informations de séquence. De plus, le nombre de bandes ou de pics détectés par ces techniques est inférieur de plusieurs ordres de grandeur à la diversité estimée dans le rumen (Hess et al 2011, Kim et al 2011). Comme dans toutes les techniques de PCR, la sélection des amorces et les problèmes intrinsèques au cours de l'amplification peuvent fausser les profils de diversité obtenus (Kanagawa 2003, Huws et al 2007). En dépit de ces faiblesses, les techniques par empreintes moléculaires sont encore utilisées car elles offrent un aperçu rapide du microbiome. Elles parviennent à montrer qu'il existe des différences entre les divers traitements, mais elles ne peuvent pas être utilisées pour cataloguer la « liste des pièces » nécessaire pour une approche de «biologie des systèmes » (Raes et Bork 2008).

\section{2 / Le séquençage et les biblio- thèques de gènes}

La diversité microbienne est davantage représentée par la constitution de bibliothèques de gènes marqueurs phylogénétiques conservés, communément les rrs, et par leur séquençage, ce qui a permis l'accumulation d'un grand nombre de séquences dérivées du rumen (Kim et al 2011). Le nombre de clones analysés par étude augmente de façon exponentielle avec le perfectionnement et la baisse du coût de la technique de séquençage de l'ADN de Sanger. Par exemple, 133 séquences ont été obtenues par Whitford et al (1998) dans l'une des premières études utilisant des banques de clones dans le rumen et 11171 séquences ont été produites par Durso et al (2010) à partir d'échantillons fécaux de bovins. Cependant, la production de données a été révolutionnée par l'apparition de techniques de séquençage de deuxième génération, notamment le pyroséquençage, qui peut produire des milliers de séquences en un seul passage, à un coût bien inférieur à celui du séquençage traditionnel avec des nucléotides fluorescents. Le rrs est devenu le marqueur phylogénétique par excellence, avec une vaste couverture de séquences comprenant tous les phylums connus à partir desquels on peut tirer des conclusions sur la classification des nouvelles séquences (Head et al 1998). Dans cet article, nous n'aborderons pas tous les avantages et inconvénients du recours aux rrs pour la classification phylogénétique des microorganismes, mais certains aspects ne doivent pas être négligés car ils peuvent affecter l'estimation de la diversité.
L'un d'eux est la présence de multiples opérons d'ARNr chez les bactéries et les archées et le fait que tous les opérons présents dans un génome microbien ne sont pas identiques. Ceci peut conduire à une surestimation de la diversité totale, qui a été calculée à environ 2,5 fois (Acinas et al 2004). En outre, lorsque la quantification est effectuée, les microorganismes possédant des nombres élevés de copies d'opérons d'ARNr seront surestimés au détriment d'espèces possédant moins de copies que la moyenne de la communauté (Crosby et Criddle 2003). Un autre aspect, plus technique, est l'erreur attribuée à la technique de pyroséquençage même et pouvant conduire à une surestimation de l'abondance des taxons. Si celle-ci n'est pas corrigée, elle peut affecter jusqu'à $35 \%$ des séquences (Gomez-Alvarez et al 2009, Quince et al 2009). La surestimation des taxons a été récemment illustrée lorsqu'un seul génome a généré des centaines de types de séquences différentes, aboutissant à des recommandations de filtrage de qualité strict, et à l'application minutieuse de limites pour les différences de séquence afin de regrouper les séquences en taxons opérationnels (Pukall et al 2009, Purushe et al 2010).

Nous avons comparé une approche de pyroséquençage pour étudier les champignons du rumen avec des banques de clones parallèles de la région des gènes ITS-1 et avons constaté que, d'une manière générale, on retrouve le même modèle de communauté en utilisant les deux techniques (Kittelmann et al 2012). En outre, la comparaison avec la DGGE a également révélé que les communautés pouvaient être différenciées par n'importe laquelle des trois méthodes. Les membres les plus rares de la communauté ont été détectés plus facilement par pyroséquençage. Cette étude a également révélé que plus de $27 \%$ des séquences fongiques de référence du rumen répertoriées dans GenBank avaient reçu une assignation incorrecte au niveau du genre, ce qui compromet les efforts visant à comparer les communautés.

Le séquençage approfondi des rrs montre que la structure de la communauté des bactéries du rumen est affectée par des changements dans la composition du régime alimentaire (Callaway et al 2010, Pitta et al 2010). La structure de la communauté dans la partie inférieure du tractus gastro-intestinal est différente de celle du rumen (Callaway et al 2010), mais aussi considérablement influencée par l'alimentation (Callaway et al 2010, Durso et al 2010, Shanks et al 2011). La complexité de l'alimentation semble favoriser la diversité. Les communautés bactériennes du rumen associées aux régimes à base de chiendent (Cynodon dactylon), riches en polyosides structurels et en composés secondaires, sont plus diversifiées que celles associées au blé fourrager en croissance (Pitta et al 2010), et la présence de polyosides hautement dégradables dans l'alimentation, tels que l'amidon, réduit le nombre d'espèces bactériennes dans les fèces (Shanks et al 2011). Comme dans d'autres microbiomes gastro-intestinaux de mammifères (Ley et al 2008a), les phylums prédominants sont les Bacteroidetes et les Firmicutes (Brulc et al 2009, Callaway et al 2010, Durso et al 2010). On estime que la diversité microbienne du tractus gastro-intestinal des ruminants est supérieure à celle de l'homme (Eckburg et al 2005, Brulc et al 2009, Durso et al 2010), avec quelques genres prédominants (20 à 25) représentant jusqu'à $90 \%$ du nombre total de séquences (Callaway et al 2010, Durso et al 2010). En fonction de la localisation dans le tube digestif et aussi probablement de l'approche technique, la proportion relative des genres peut changer. Cependant, la plupart des études a identifié Prevotella comme étant un genre important, si ce n'est le genre dominant de la communauté. Ces études ont également montré que les genres cellulolytiques cultivés tels que Ruminococcus et Fibrobacter ne sont pas parmi les plus abondants de la communauté, et ont détecté la présence de plusieurs autres genres dégradant les fibres (Brulc et al 2009, Pitta et al 2010).

Le séquençage complet couvre la diversité microbienne d'une manière utile et élargie, permettant ainsi d'identifier les membres « centraux» les plus communs dans la communauté, mais également les membres « rares » qui pourraient être associés aux pratiques alimentaires (Shanks et al 2011). Les membres rares ne sont pas détectables par des techniques moins sensibles (PedrosAlio 2006). Néanmoins, cet ensemble de données étendu sur les rrs confirme généralement des informations qui ont été suggérées par des approches d'empreintes moléculaires ou de séquençage de banques de clones de petite taille. L'approche du séquençage des gènes rrs est une bonne méthode pour effectuer une classification phylogénétique initiale de nouveaux microorganismes, pas encore cultivés, jusqu'au niveau du genre. Toutefois, la résolution des informations contenues dans ce seul gène n'est pas suffisante pour définir une espèce (RossellóMora et Amann 2001). L'utilisation d'un ensemble étendu de gènes marqueurs offre une meilleure image qualitative et quantitative des communautés naturelles (von Mering et al 2007). Fait important, ces auteurs ont également déterminé qu'il n'existe pas de parallèle automatique entre la similarité phylogénétique et le phénotype ou la fonction microbienne. Les microorganismes phylogéné- 
tiquement proches peuvent souvent avoir des fonctions et des caractéristiques métaboliques différentes (Achenbach et Coates 2000, von Mering et al 2007), ce qui souligne l'importance de caractériser les propriétés fonctionnelles de l'écosystème.

\section{3 / Projets concernant les gé- nomes microbiens du rumen}

Les premières études menées sur les gènes individuels des microorganismes du rumen étaient basées sur la détection de gènes provenant des bibliothèques d'ADN génomique via des criblages fonctionnels ou, plus récemment, via amplification par PCR de gènes d'intérêt et de leurs homologues. En revanche, seules les activités de ces gènes correctement exprimés dans des souches de $E$. coli ont été détectées, menant inévitablement à une sous-estimation considérable des gènes présents. Les premiers gènes identifiés à travers ces approches codaient des cellulases de Fibrobacter succinogenes (Crosby et al 1984). Par la suite, sept gènes de $F$. succinogenes codant des enzymes de dégradation des fibres ont été trouvés grâce à ces approches génétiques conventionnelles (Forsberg et al 2000). Lorsque le génome de Fibrobacter succinogenes S85 a été séquencé, il a révélé 104 cadres ouverts de lecture (ORF) prédits comme codant des enzymes participant à la dégradation des parois végétales, dont 33 cellulases, 24 xylanases et 14 estérases (Jun et al 2007). Cet exemple illustre bien la force du séquençage des génomes, le génome $F$. succinogenes ayant montré un potentiel enzymatique plusieurs fois supérieur à celui de toutes les études précédentes sur cet organisme.

Les progrès technologiques ont permis au séquençage du génome de devenir plus simple et abordable. Ces dernières années, le rythme de séquençage du génome des bactéries du rumen a continué de s'accélérer et a apporté un élan considérable à la microbiologie du rumen. Il existe actuellement 16 séquences génomiques accessibles de microorganismes du rumen (tableau 1), dont la moitié sont des génomes complets. Ces projets de séquençage ont des objectifs différents, de la découverte de nouveaux gènes codant des activités de dégradation des fibres pour améliorer la production animale ou pour la dépolymérisation des matières premières visant la production de biocarburants, jusqu'à l'atténuation des émissions de méthane par les ruminants au travers d'interventions contre les méthanogènes. Ces projets apportent également des technologies fonctionnelles « omiques » permettant de parvenir à une meilleure compréhension des fonctions des gènes au sein de ces organismes. L'expression différentielle de gènes (transcriptomique) et l'expression des protéines (protéomique) ou la production de métabolites (métabolomique), sont utilisées pour confirmer les fonctions des gènes annotés et tester les hypothèses sur le rôle des gènes « inconnus » ou « hypothétiquement conservés ».

Les séquences des génomes bactériens obtenues à ce jour ont apporté une immense quantité de séquences génétiques à la base de données grandissante des gènes microbiens du rumen. Les génomes bactériens complets permettent d'identifier à eux seuls actuellement plus de 27000 séquences protéiques codantes (CDS), et il est probable que ce chiffre soit multiplié par deux dans un avenir proche avec la résolution de plusieurs ébauches de génomes et le lancement de nouveaux projets de séquençage de génomes microbiens du rumen. Cette connaissance peut apporter une contribution bénéfique à certains aspects des processus digestifs des ruminants et peut également influencer positivement les produits des ruminants. Comme indiqué dans le tableau 1, la majorité des projets actuels de séquençage de génome visent les bactéries de dégradation de la cellulose et des hémicelluloses, et on peut en attendre des bénéfices pour la production des ruminants dans le domaine de la dégradation des fibres du rumen. Les polyosides structurels forment des ensembles complexes au sein de la paroi des cellules végétales et une gamme d'activités enzymatiques est nécessaire pour les dégrader. On trouve ces activités enzymatiques dans une grande variété de microorganismes phylogénétiquement distincts, principalement dans les bactéries, mais aussi dans les champignons et, à un degré moindre, dans les protozoaires.

Plus récemment, les données de métagénomique du rumen ont permis de commencer à reconstruire des génomes bactériens individuels. En effet, l'étude de séquençage métagénomique approfondie réalisée par Hess et al (2011) a permis d'assembler correctement 15 ébauches de génomes contenant entre $60 \%$ et $93 \%$ de leurs gènes centraux respectifs. Par ailleurs, des données de séquences de génome de cellules microbiennes individuelles non cultivées, isolées directement de la communauté complexe du rumen ont été obtenues en utilisant des techniques d'isolement «single cell». Après amplification du génome entier, une des cellules individuelles analysées correspondait au groupe de génomes $\mathrm{APb}$, l'un des plus grands groupes assemblés à partir des données de metagénomiques. La séquence $r r s$ indiquait que l'organisme était relié à Butyrivibrio fibrisolvens.
Nous avons ensuite analysé le groupe de génomes $\mathrm{APb}(2,41 \mathrm{Mpb})$ et découvert qu'il correspond à l'ébauche de génome d'une souche de Butyrivibrio hungatei (3,37 Mpb, Palevich et al, non publié).

\section{1 / Que révèlent les génomes des bactéries fibrolytiques du rumen sur leurs stratégies de dégradation des polyosides com- plexes?}

Chaque espèce de bactéries responsables de la solubilisation des polyosides végétaux semble adopter une stratégie différente d'hydrolyse des fibres. La souche $F$. succinogenes $\mathrm{S} 85$ ne peut métaboliser que les produits de dégradation de la cellulose. En effet, bien que son génome code une série d'enzymes capables d'hydrolyser une vaste gamme de polyosides des parois cellulaires végétales, il manque à $F$. succinogenes des gènes codant les protéines de transport ou les enzymes impliquées dans le métabolisme des polyosides non cellulosiques tels que les xylanes. Ainsi, elle semble coder les activités enzymatiques en ciblant les polyosides non cellulosiques uniquement pour ouvrir le passage vers son substrat principal, la cellulose. Seules de faibles activités extracellulaires de cellulase peuvent être détectées dans le surnageant des cultures de F. succinogenes (Groleau et Forsberg 1981), et la fixation de la bactérie sur des substrats cellulosiques solides semble être une condition préalable à la dégradation de la cellulose (Kudo et al 1987, Weimer et Odt 1995). F. succinogenes ne possède pas de composants des cellulosomes tels que les dockerines, cohésines et scaffoldines (voir ci-dessous) (Doi et Kosugi 2004). Ainsi, il semble que la dégradation de la cellulose par $F$. succinogenes implique une interaction synergique significative entre la cellule et ses enzymes (Lynd et al 2002) et qu'elle pourrait bien impliquer un processus non-enzymatique (Brumm et al 2011).

L'espèce Ruminococcus flavefaciens code un large éventail d'enzymes dont on prévoit la sécrétion par la cellule et l'assemblage en un échafaudage extrêmement organisé, appelé cellulosome, qui joue le rôle de médiateur dans l'adhésion et la dégradation des fibres végétales. Les gènes identifiés dans le génome de Ruminococcus flavefaciens FD-1 indiquent qu'il peut utiliser toute une gamme de polyosides des parois cellulaires végétales (Berg Miller et al 2009). Ils confirment également la présence d'un complexe multienzymatique de type cellulosome dans lequel les enzymes sont liées à une structure d'échafaudage non catalytique par l'intermédiaire de domaines appelés dockerines. L'organisation 
des cellulosomes chez FD-1 est extrêmement complexe et plus de 200 protéines contenant des dockerines ont été identifiées à partir de la séquence du génome (Rincon et al 2010). L'analyse de l'expression des gènes dans cet organisme indique que le type de substrat utilisé par $R$. flavefaciens FD-1 peut influencer la composition enzymatique du cellulosome.

Le génome de R. albus 7 est désormais complet et a été déposé sur le site Web de l'Institut JGI (http://genome. jgi-psf. org/rumal/rumal.info.html). Ce génome est organisé dans un chromosome d'environ 3,7 Mpb, avec 2 mégaplasmides de $420 \mathrm{kpb}$ et $352 \mathrm{kpb}$, et 2 plasmides de plus petite taille, de $15,9 \mathrm{kpb}$ et 7,4 kpb. Sur la base de notre analyse de la séquence du génome de $R$. albus 7, il contient beaucoup moins de protéines de type dockerine que $R$. flavefaciens FD-1. $R$. albus 7 possède 29 protéines contenant des dockerines, dont 25 sur le chromosome principal, 3 sur le plasmide de
$420 \mathrm{kpb}$ et 1 sur le plasmide de $352 \mathrm{kpb}$. Plusieurs de ces protéines à dockerines contiennent des domaines de dégradation des polyosides. Bien que la séquence du génome de $R$. albus 8 soit moins bien annotée, elle semble avoir environ 40 protéines identifiées comme contenant des dockerines de type I (http://www.jcvi.org/ rumenomics). Le plus petit nombre de protéines à dockerines indique vraisemblablement que $R$. albus possède un cellulosome moins bien développé que $R$. flavefaciens. La séquence incomplète du

Tableau 1. Séquences génomiques de bactéries du rumen disponibles publiquement.

\begin{tabular}{|c|c|c|c|c|c|}
\hline Organisme & Contigs & $\begin{array}{l}\text { Taille } \\
\text { (pb) }\end{array}$ & $\mathbf{G}+\mathbf{C} \%$ & Famille & $\begin{array}{l}\text { Centre de séquençage, } \\
\text { référence }{ }^{(a)}\end{array}$ \\
\hline \multicolumn{6}{|l|}{ Bactéries fibrolytiques } \\
\hline \multirow[t]{4}{*}{ Butyrivibrio proteoclasticus B316 ${ }^{\text {(b) }}$} & 1 & 3555059 & 40 & \multirow[t]{4}{*}{ Lachnospiraceae } & \multirow{4}{*}{$\begin{array}{l}\text { AgResearch, } \\
\text { Kelly et al (2010) }\end{array}$} \\
\hline & 1 & 361399 & 39 & & \\
\hline & 1 & 302355 & 40 & & \\
\hline & 1 & 186328 & 38 & & \\
\hline Eubacterium cellulosolvens 6 & 107 & 3260436 & 48 & Lachnospiraceae & JGI \\
\hline Prevotella bryantii $\mathrm{B}_{1} 4$ & 98 & 3592947 & 39 & Prevotellaceae & $\begin{array}{c}\text { NACGFRB, } \\
\text { Purushe et al (2010) }\end{array}$ \\
\hline Prevotella ruminicola $23^{\mathrm{b}}$ & 1 & 3619559 & 47 & Prevotellaceae & $\begin{array}{c}\text { NACGFRB, } \\
\text { Purushe et al (2010) }\end{array}$ \\
\hline Fibrobacter succinogenes $\mathrm{S} 85^{\mathrm{b}}$ & 1 & 3842635 & 48 & Fibrobacteraceae & $\begin{array}{l}\text { JGI/NACGFRB, } \\
\text { Suen et al (2011) }\end{array}$ \\
\hline \multirow[t]{5}{*}{ Ruminococcus albus $7^{\mathrm{b}}$} & 1 & 3685408 & 44 & \multirow[t]{5}{*}{ Ruminococcaceae } & \multirow[t]{5}{*}{ JGI } \\
\hline & 1 & 420706 & 38 & & \\
\hline & 1 & 352646 & 44 & & \\
\hline & 1 & 15907 & 36 & & \\
\hline & 1 & 7420 & 42 & & \\
\hline Ruminococcus albus 8 & 245 & 4373730 & 46 & Ruminococcaceae & NACGFRB \\
\hline Ruminococcus flavefaciens FD-1 & 119 & 4573608 & 45 & Ruminococcaceae & $\begin{array}{c}\text { NACGFRB, } \\
\text { Berg Miller et al (2009) }\end{array}$ \\
\hline \multicolumn{6}{|l|}{ Autres bactéries } \\
\hline Actinobacillus succinogenes $130 \mathrm{Z}^{\mathrm{b}}$ & 1 & 2319663 & 44 & Pasteurellaceae & JGI \\
\hline Desulfotomaculum ruminis DSM 2154 & 66 & 3864667 & 47 & Peptococcaceae & JGI \\
\hline $\begin{array}{l}\text { Desulfovibrio desulfuricans subsp. } \\
\text { desulfuricans str. ATCC } 27774^{\mathrm{b}}\end{array}$ & 1 & 2873437 & 58 & Desulfovibrionaceae & JGI \\
\hline Basfia succiniciproducens MBEL55E ${ }^{\mathrm{b}}$ & 1 & 2314078 & 42 & Pasteurellaceae & $\begin{array}{c}\text { KAIST, } \\
\text { Hong et al (2004) }\end{array}$ \\
\hline Slackia heliotrinireducens DSM $20476^{\text {b }}$ & 1 & 3165038 & 60 & Coriobacteriaceae & JGI, Pukall et al (2009) \\
\hline Treponema saccharophilum DSM 2985 & 56 & 3453897 & 53 & Spirochaetaceae & $\mathrm{JGI}$ \\
\hline Wolinella succinogenes DSM $1740^{\mathrm{b}}$ & 1 & 2110355 & 48 & Helicobacteriaceae & MPI, Baar et al (2003) \\
\hline Megasphaera elsdenii DSM 20460 & 1 & 2474718 & 53 & Veillonellaceae & BOKU, Marx et al (2011) \\
\hline
\end{tabular}

${ }^{a}$ NACGFRB : North American Consortium for the Genomics of Fibrolytic Rumen Bacteria ; JGI : Joint Genome Institute ; KAIST : Korea Advanced Institute of Science and Technology; MPI : Max Planck Institute ; BOKU University of Natural Resources and Life Sciences, Vienna, Austria.

${ }^{\mathrm{b}}$ Génomes complets. 
génome de $R$. albus 8 avait été utilisée auparavant pour identifier les protéines impliquées dans l'adhésion et la dégradation de la cellulose (Devillard et al 2004). Par rapport à la souche de type sauvage, les souches mutantes de $R$. albus 8 défaillantes en termes de dégradation de la cellulose sont dépourvues de deux protéines de haute masse molaire, qui ont été identifiées comme endocellulases Cel48A et Cel9B. Les espèces Butyrivibrio et Pseudobutyrivibrio ont fait l'objet récemment d'un regain d'intérêt en raison de leurs fortes capacités de dégradation du xylane et la prévalence de leurs gènes rrs dans les banques de séquences extraites des contenus ruminaux (Attwood et al 2004, Moon communication personnelle). Le récent séquençage du génome de Butyrivibrio proteoclasticus a identifié un grand nombre de gènes impliqués dans l'utilisation des polyosides végétaux, notamment les hémicelluloses (Kelly et al 2010). Ceux-ci comprennent des glycoside hydrolases $[\mathrm{GH}]$, (principalement des familles $2,3,5,10,13$, et 43 des feruloyl- et des acétyl-xylane estérases, ainsi qu'une variété de pectates lyases. Plusieurs des GH de B. proteoclasticus sont annotées comme appartenant à différentes catégories de xylanases, de xylosidases ou d'arabinosidases, corrélant à la capacité de la bactérie à bien se développer sur le xylane. Cependant, bien que le $B$. proteoclasticus soit incapable de croître sur de la cellulose comme source de carbone, deux gènes de cellulase sont présents. Une analyse protéomique a montré qu'au moins une de ces cellulases est exprimée de manière constitutive au cours de la croissance sur le xylane ou le xylose (Dunne et al 2007). Bien que les activités exactes de ces enzymes n'aient pas été définies, il semble probable qu'elles contribuent en améliorant l'accès aux hémicelluloses et aux pectines, qui semblent être les substrats préférentiels de $B$. proteoclasticus. Une caractéristique intéressante des enzymes de $B$. proteoclasticus impliquées dans la dégradation des polyosides est le fait que la plupart seraient localisées au sein de la cellule. Cette localisation présumée des enzymes suggère qu'un nombre limité d'enzymes sécrétées génère une variété d'oligosaccharides complexes qui sont ensuite transportés dans la cellule pour être dégradés et métabolisés. Le regroupement des gènes codant des enzymes intracellulaires dégradant les polyosides, avec des gènes codant pour les transporteurs, les régulateurs de la transcription et les senseurs environnementaux dans des locus d'utilisation des polyosides (Kelly et al 2010), soutient ce modèle. Les données d'expression génique suggèrent également une coexpression de ces gènes lorsque $B$. proteoclasticus croît sur un substrat insoluble, le xylane. L'expression coordonnée des enzymes de dégradation des polyosides avec des transporteurs de sucre est probablement un mécanisme permettant de réduire la concurrence des microorganismes saccharolytiques en limitant la quantité de saccharides prêts à être utilisés et libérés dans le milieu environnant. Il a également été démontré que $B$. proteoclasticus adhère à la matière végétale et que, outre ses vastes capacités de dégradation de l'hémicellulose, ceci implique qu'il est capable de coloniser et de dégrader les plantes dans l'environnement du rumen. Étant donné que l'on suppose que l'hémicellulose entoure la cellulose dans la plupart des modèles de parois cellulaires végétales et qu'elle serait donc l'un des premiers polyosides végétaux rencontrés par les bactéries envahissantes, il est possible que le $B$. proteoclasticus soit une bactérie de colonisation et dégradation initiale du matériel végétal dans le rumen.

\section{2 / Projets de séquençage du génome des méthanogènes du rumen}

Le méthane est un gaz à effet de serre important et les émissions provenant de sources agricoles représentent environ $40 \%$ du méthane d'origine anthropique total, dont $25 \%$ provient directement de la fermentation entérique du bétail (Olivier et al 2005). Il existe plusieurs projets de séquençage du génome des méthanogènes du rumen en cours ou terminés, qui optimisent notre compréhension de la diversité et de la capacité métabolique des archées méthanogènes dans le rumen (tableau 2).

Le génome de Methanobrevibacter ruminantium $\mathrm{M} 1$ fut le premier génome de méthanogène du rumen à être séquencé. Cette information de séquençage a confirmé le mode de vie hydrogénotrophe de $M$. ruminantium $\mathrm{M} 1$ tandis que des

Tableau 2. Projets de séquençage du génome de méthanogènes du rumen.

\begin{tabular}{|c|c|c|c|c|c|}
\hline Ordre & Genre & $\begin{array}{l}\text { Espèce/(clade ou } \\
\text { parent plus proche) }\end{array}$ & Souche & Origine $^{(\mathbf{b})}$ & Statut ${ }^{(c)}$ \\
\hline Methanobacteriales & $\begin{array}{l}\text { Methanobrevibacter } \\
\text { Methanobacterium } \\
\text { Methanobrevibacter } \\
\text { Methanosphaera }\end{array}$ & $\begin{array}{l}\text { Ruminantium } \\
\text { (gottschalkii) } \\
\text { Bryantii } \\
\text { (formicicum) } \\
\text { (wolinii) } \\
\text { (stadtmanae) }\end{array}$ & $\begin{array}{l}\text { M1 } \\
\text { YLM1 } \\
\text { YE286 } \\
\text { SM9 } \\
\text { YE299 } \\
\text { BRM9 } \\
\text { ABM4 } \\
\text { 3F5 }\end{array}$ & $\begin{array}{l}\text { Bovine } \\
\text { Ovine } \\
\text { Bovine } \\
\text { Ovine } \\
\text { Bovine } \\
\text { Bovine } \\
\text { Ovine } \\
\text { Ovine }\end{array}$ & $\begin{array}{l}\text { Complet } \\
\text { Incomplet } \\
\text { Incomplet } \\
\text { Complet } \\
\text { Incomplet } \\
\text { Complet } \\
\text { Incomplet } \\
\text { Incomplet }\end{array}$ \\
\hline Methanosarcinales & Methanosarcina & (barkeri) & CM1 & Bovine & Incomplet \\
\hline $\begin{array}{l}\text { Thermoplasmales-associated } \\
\text { lineage C (TALC) }\end{array}$ & Not assigned & (Thermoplasma sp.) & TALC & Bovine & Complet \\
\hline
\end{tabular}

(a) Espèces valablement attribuées, ou clade selon Janssen et Kirs (2008) ou plus proche parent cultivé, tel que déterminé par la similarité de séquence du gène de la petite sous-unité d'ARN ribosomal.

(b) Toutes les souches ont été initialement isolées de contenu du rumen, sauf ABM4 qui a été isolée à partir de la caillette d'ovin.

(c) Espèces méthanogènes séquencées dans le cadre des programmes suivants : M1 et SM9, NZ Pastoral Greenhouse Gas Research Consortium; YLM1 et BRM9, NZ Ministry of Agriculture and Forestry Sustainable Land Management and Climate Change Fund; 3F5 and ABM4, NZ Agricultural Greenhouse Gas Research Centre; YE 286 and YE299, Commonwealth Scientific and Industrial Research Organisation-Queensland Department of Primary Industry and Beef Cooperative Research Centre; TALC, Commonwealth Scientific and Industrial Research Organisation, Livestock Industries. 
études d'expression génique ont indiqué que le formiate est peut-être un substrat important pour la méthanogénèse durant la croissance syntrophique avec les bactéries du rumen (Leahy et al 2010). Il a également été présumé et montré que les alcools à chaîne courte stimulent la croissance sur les substrats hydrogène $/ \mathrm{CO}_{2}$, mais ne permettent pas la croissance à eux seuls. Une des originalités observées lors de l'analyse du génome de $M$. ruminantium a été l'absence de gènes codant le système d'enzymes de la méthyle-coenzyme $M$ réductase II (Mcr II), une isoenzyme de l'enzyme Mcr I, qui se trouve généralement dans les méthanogènes hydrogénotrophes d'autres écosystèmes. Dans les méthanogènes non-hydrogénotrophes, le système Mcr II est régulé de façon différentielle au cours de la croissance (Reeve et al 1997, Luo et al 2002), et l'on suppose qu'il joue un rôle de médiateur dans la formation de méthane à des pressions partielles d'hydrogène élevées. Dans le rumen, les méthanogènes dépendent des microorganismes fermentaires pour leur fournir de l'hydrogène, qui est généralement maintenu à de très faibles concentrations (Janssen 2010). L'absence d'un système Mcr II chez $M$. ruminantium suggère qu'il est adapté à la croissance en présence de faibles niveaux d'hydrogène, avec uniquement le système Mcr I.

Comme dans les génomes des archées méthanogènes intestinales humaines Methanosphaera stadtmanae (Fricke et al 2006) et Methanobrevibacter smithii (Samuel et al 2007), le génome de $M$. ruminantium code des protéines de surface qui ont des caractéristiques semblables à celles des adhésines bactériennes facilitant l'adhésion aux surfaces. Le rôle de ces protéines est méconnu, mais lors d'expériences en co-culture, des gènes codant plusieurs de ces protéines de type adhésines ont été surexprimés et l'examen microscopique a montré la co-agrégation de cellules de $M$. ruminantium et de B. proteoclasticus (Leahy et al 2010). L'abondance de gènes codant ces protéines de type adhésine dans le génome de $M$. ruminantium indique une importante capacité à moduler la topologie de la surface cellulaire, et suggère un rôle probable de médiation de liens étroits avec des bactéries, champignons et protozoaires produisant de l'hydrogène. Outre les protéines de type adhésine, M. ruminantium code plus de 50 gènes impliqués dans la synthèse et l'exportation d'exopolysaccharides. Ceci est en accord avec la production d'une capsule par M. ruminantium (Kandler et König 1978, Kandler et König 1985).

Une découverte inattendue dans la séquence du génome de $M$. ruminantium fut la présence d'une séquence d'un prophage de méthanogènes, désigné $\varphi$ mru
(Attwood et al 2008, Leahy et al 2010). L'analyse de la séquence du prophage pmru a identifié des gènes codant la fonction de lyse cellulaire. Un de ces gènes, codant pour une endoisopeptidase désignée PeiR, a été sous-cloné et exprimé chez E. coli et il a été démontré qu'il joue un rôle dans la lyse cellulaire de M. ruminantium in vitro (Leahy et al 2010). La découverte de deux gènes de peptide synthétases non ribosomiques (NRPS) a également été surprenante, car ils ont été les premiers à être observés dans un génome archéen. Une vaste gamme d'activité a été attribuée aux peptides non ribosomiques (PNR), mais dans ce cas, ni le peptide produit par le gène de $M$. ruminantium NRPS, ni sa fonction ne sont connus.

\section{4 / La recherche de fonctions à travers la métagénomique}

La métagénomique est l'analyse de séquences obtenues à partir d'un échantillon comprenant plusieurs espèces microbiennes. La métagénomique fonctionnelle consiste à exprimer ces séquences lorsqu'elles sont insérées dans un vecteur tandis que la métagénomique basée sur des séquences repose sur la comparaison des séquences avec une base de données.

\section{1 / Métagénomique fonctionnelle}

Parce que le rumen a évolué pour devenir un système de dégradation de la lignocellulose efficace et complexe, il a fait l'objet d'études métagénomiques visant à déterminer et saisir la diversité des activités enzymatiques présentes. La métagénomique fonctionnelle est utilisée pour identifier les enzymes hydrolytiques d'intérêt biotechnologique en utilisant des substrats spécifiques, en particulier des enzymes impliquées dans la déconstruction des polyosides structurels végétaux. Cette approche a été initiée par Ferrer et al (2005), qui ont détecté neuf endoglucanases, douze estérases et une cyclodextrinase à partir d'une bibliothèque métagénomique du rumen de vaches laitières. Par la suite, plusieurs groupes ont utilisé les bibliothèques métagénomiques afin d'isoler certaines enzymes de dégradation des polyosides provenant du rumen (tableau 3). Cette approche dépend de la disponibilité des essais biologiques appropriés pour les activités d'intérêt, et à ce jour l'attention s'est portée principalement sur la dégradation de la cellulose et de l'hémicellulose. Les bibliothèques métagénomique du rumen ont également été utilisées avec succès pour rechercher d'autres activités biologiques, y compris de nouvelles lipases (Liu et al 2009, Bayer et al 2010), polyphénol oxydase (Beloqui et al 2006), et une enzyme capable de dégrader le 3,5,6-trichloro-2-pyridinol, un produit de dégradation du chlorpyrifos, un insecticide organophosphoré (Math et al 2010). En outre, des gènes de phytases ont été isolés par criblage de l'ADN génomique de rumen de vaches et de chèvres en utilisant des amorces dégénérées (Huang et al 2010).

La métagénomique fonctionnelle permet de découvrir de nouvelles enzymes et voies métaboliques dans le rumen si des stratégies novatrices pour le criblage sont développées. Le mécanisme enzymatique nécessaire pour hydrolyser les polyosides végétaux structurels est un objectif évident, mais les domaines catalytiques retrouvés à ce jour appartiennent tous à des familles connues. D'autres objectifs potentiels comprennent la biotransformation de composés d'intérêt pour l'animal ou le consommateur, tels que les antioxydants et les acides linoléiques conjugués, ou la détoxification de toxines végétales, de mycotoxines et de xénobiotiques. D'autres stratégies utilisées dans le criblage métagénomique fonctionnel sont la complémentation hétérologue de souches mutantes et l'induction de gènes rapporteurs (Simon et Daniel 2011). Un des inconvénients de ces techniques est le fait que les hôtes microbiens d'expression n'expriment pas toujours les protéines d'autres groupes taxonomiques sous une forme fonctionnelle.

\section{2 / Métagénomique et méta- transcriptomique basée sur les séquences}

L'exploration des microorganismes présents dans l'intestin des mammifères à travers la métagénomique basée sur les séquences est une technique récente qui reflète l'attention croissante accordée au rôle des communautés microbiennes intestinales sur la santé de l'hôte. Cet élan provient de grands projets de séquençage des communautés microbiennes intestinales de l'Homme soutenues par l'Union européenne (www.metahit.eu) et les Instituts Nationaux de la Santé aux États-Unis (projet portant sur le microbiome humain, https://commonfund.nih. gov/hmp). Nous avons connaissance de nombreux projets en cours utilisant une approche de métagénomique ou de métatranscriptomique (cf. encadré) sur le microbiome du rumen, mais il existe encore peu de rapports publiés. Bien que des approches différentes aient été utilisées, de grandes études basées sur les séquences ont commencé à cataloguer les gènes présents et à examiner les processus du rumen impliqués dans la dégradation des fibres (Brulc et al 2009). L'importance de l'exploration de l'environnement du rumen selon ce procédé a été démontrée par l'étude du JGI mettant l'accent sur la communauté micro- 
Tableau 3. Enzymes dégradant les polyosides végétaux identifiées à partir des bibliothèques métagénomiques du rumen.

\begin{tabular}{|c|c|c|c|}
\hline Famille CAZy & Activité (nombre) & Animal & Référence \\
\hline $\mathrm{GH} 3$ & $\beta$-glucosidase & Vache & Wang et al (2009) \\
\hline GH3 & $\beta$-xylosidase & Vache & Shedova et al (2009) \\
\hline GH3 & non spécifiée (15) & Vache & Hess et al (2011) \\
\hline GH5 & endo-glucanase (7) & Vache & Ferrer et al (2005) \\
\hline GH5 & cellodextrinase (2) & Buffalo & Duan et al (2009) \\
\hline GH5 & endo-glucanase (12) & Buffalo & Duan et al (2009) \\
\hline GH5 & endo- $\beta-1,4$-glucanase & Buffalo & Liu et al (2009b) \\
\hline GH5 & endo- $\beta-1,4-$ glucanase & Vache & Shedova et al (2009) \\
\hline GH5 & endo- $\beta-1,4$-glucanase (2) & Vache & Wang et al (2009) \\
\hline GH5 & endo-xyloglucanase & Vache & Wong et al (2010a) \\
\hline GH5 & exo-xyloglucanase & Vache & Wong et al (2010b) \\
\hline GH5 & non spécifiée (27) & Vache & Hess et al (2011) \\
\hline GH5 & endo-glucanase/xylanase & Yak & Chang et al (2011) \\
\hline GH5/GH26 & glucanase/mannanase/xylanase & Vache & Palackal et al (2007) \\
\hline GH5/GH26 & non spécifiée (1) & Vache & Hess et al (2011) \\
\hline GH8 & non spécifiée (2) & Vache & Hess et al (2011) \\
\hline GH9 & non spécifiée (20) & Vache & Hess et al (2011) \\
\hline GH10 & non spécifiée (21) & Vache & Hess et al (2011) \\
\hline GH13 & cyclomaltodextrinase & Vache & Ferrer et al (2007) \\
\hline $\mathrm{GH} 26$ & endo-glucanase (2) & Vache & Ferrer et al (2005) \\
\hline $\mathrm{GH} 26$ & mannanase (2) & Buffalo & Duan et al (2009) \\
\hline GH26 & non spécifiée (1) & Vache & Hess et al (2011) \\
\hline $\mathrm{GH} 43$ & exo- $\alpha-1,5$-L-arabinase & Vache & Wong et al (2008) \\
\hline $\mathrm{GH} 43$ & endo- $\alpha-1,5$-L-arabinase & Vache & Wong et al (2009) \\
\hline $\mathrm{GH} 43$ & arabinosidase/xylosidase (3) & Vache & Zhao et al (2010) \\
\hline $\mathrm{GH} 43$ & endo-xylanase & Vache & Zhao et al (2010) \\
\hline $\mathrm{GH} 48$ & non spécifiée & Vache & Hess et al (2011) \\
\hline GH57 & $\alpha$-amylase & Vache & Zhao et al (2010) \\
\hline CE6 & acetyl-xylane estérase & Vache & López-Cortés et al (2007) \\
\hline- & estérase non spécifiée (11) & Vache & Ferrer et al (2005) \\
\hline- & estérase non spécifiée (2) & Vache & Zhao et al (2010) \\
\hline
\end{tabular}

bienne attachée à du panic érigé (Panicum virgatum) incubé dans le rumen des vaches laitières (Hess et al 2011, tableau 3), et par l'analyse métatranscriptomique du rumen du bœuf musqué, qui a mis l'accent sur les champignons et protozoaires anaérobies (Qi et al 2011). Le tableau 4 compare la répartition des principales familles de glycoside hydrolases impliquées dans la dégradation des polyosides végétaux dans ces études de métagénomique ou de métatranscrip- tomique, ainsi que dans les quatre bactéries fibrolytiques du rumen, dont les génomes ont été entièrement séquencés. A noter que les familles de GH impliquées dans la dégradation de la cellulose sont bien représentées dans les deux bactéries cellulolytiques (F. succinogenes et $R$. albus) ainsi que dans le métatranscriptome eucaryote microbien des bœufs musqués, mais moins répandues dans les autres études. Les profils métagénomiques semblent plus semblables à ceux des organismes dégradant l'hémicellulose et la pectine (Butyrivibrio et Prevotella). Dans l'ensemble, les principales activités des GH trouvées (GH43, GH3, GH2, GH13) sont en corrélation avec celles détectées dans les métagénomes d'autres environnements microbiens (Li et al 2008).

Il serait utile que les données métagénomiques basées sur les séquences soient placées dans un contexte taxonomique. 
Tableau 4. Profils des principales familles de Glycoside Hydrolase (GH) impliquées dans la dégradation des polyosides végétaux dans le rumen.

Les valeurs indiquées représentent le pourcentage du total des $\mathrm{GH}$ présentes dans chaque espèce / métagénome / métatranscriptome. Les cinq dernières colonnes indiquent les substrats sur lesquels les différentes familles d'enzymes sont actives.

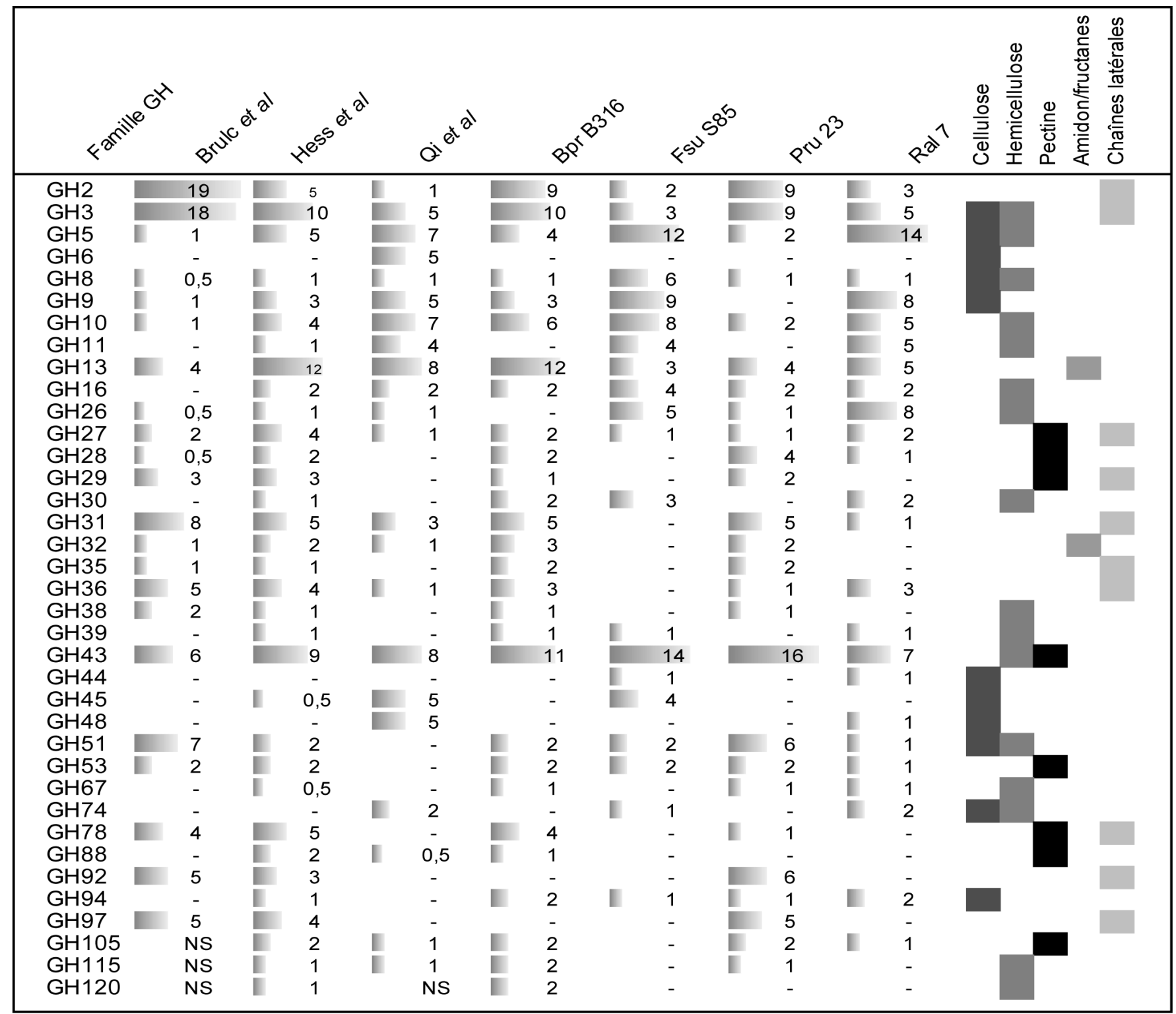

NS : Non Signalé.

Les données proviennent de deux études métagénomiques du rumen de bovins (Brulc et al 2009, Hess et al 2011), de l'étude de métatranscriptomique des eucaryotes du rumen du bœuf musqué (Qi et al 2011), et des séquences génomiques complètes de quatre bactéries fibrolytiques du rumen : Butyrivibrio proteoclasticus B316 (Kelly et al 2010), Fibrobacter succinogenes S85 (Suen et al 2011), Prevotella ruminicola 23 (Purushe et al 2010) et Ruminococcus albus 7 . Les informations sur leurs profils GH ont été obtenues à partir de la base de données CAZy (http://www.cazy.org/). L'analyse des familles de GH non incluses dans les publications originales a été réalisée comme décrit par Warnecke et al (2007).

L'analyse des données métagénomiques serait en effet facilitée par l'existence d'un ensemble de séquences des génomes microbiens du rumen de référence, analogue au catalogue des génomes de référence du microbiome humain (The Human Microbiome Jumpstart Reference Strains 2010), servant à étayer l'analyse des ensembles de données métagénomiques de l'intestin humain. L'importance des génomes de référence pour ce type d'analyse est visible dans les progrès rapides accomplis dans ce domaine de la recherche (Arumugam et al 2011). Concernant la métatranscriptomique, un nouveau logiciel peut désormais gérer les données de séquence d'ARN sans avoir recours aux génomes de référence (Grabherr et al 2011), mais celui-ci n'a pas encore été testé dans des écosystèmes complexes tels que le rumen. Néanmoins, un plus grand nombre de génomes disponibles et un catalogue des gènes de référence de bonne qualité ne peuvent que renforcer l'espoir que la métatranscriptomique révèle de nouveaux traits fonctionnels.

\section{5 / Lier les données de géno- mique et de métagénomique à la nutrition et à d'autres caractéristiques de la pro- duction animale}

Le catalogage des gènes et des fonctions du microbiome est une étape indispensable pour modéliser et lier le métabolisme microbien du rumen à celui de l'hôte (Raes et Bork 2008, Karlsson et al 2011). 
Traditionnellement, les caractéristiques de la nutrition et de la production chez les ruminants ont été évaluées sans tenir compte du microbiome du rumen. Désormais, l'inclusion de cette « composante » du super-organisme offre une bonne opportunité d'améliorer notre compréhension des caractéristiques digestives et biologiques de l'hôte. Comme indiqué dans les parties précédentes, le microbiome du rumen est complexe, extrêmement diversifié, et son catalogue de gènes est incomplet. En considérant des concepts écologiques, la diversité taxonomique et fonctionnelle du microbiome devrait assurer de hauts niveaux de redondance et, par conséquent, de la stabilité (Konopka 2009). La stabilité assure le maintien des fonctions suite à des changements dans le régime alimentaire ou à d'autres contraintes environnementales. Cependant, plusieurs questions écologiques fondamentales restent sans réponse. Les membres et les fonctions essentiels de la communauté doivent être définis de manière concluante afin de répondre à des questions simples mais pertinentes, telles que : Les microorganismes du rumen numériquement dominants sontils tous des membres clés de la communauté ? Certaines fonctions clés sont peut-être assurées par des membres rares. Les membres rares constituent une « assurance » pour l'hôte lors des changements environnementaux, comme cela a été décrit pour certains microorganismes spécialisés dégradant les toxines végétales (Weimer 1998), mais bien d'autres fonctions peuvent être cachées au sein des membres rares de la communauté (Pedros-Alio 2006).

Récemment, Muegge et al (2011) ont démontré que les microbiomes des mammifères ont un grand nombre de fonctions en commun, ce qui implique que des résultats obtenus à partir d'études sur les humains et d'autres animaux peuvent renseigner les concepts généraux appliqués aux ruminants. Les lignées (divisions) microbiennes restent associées à un environnement donné (von Mering et al 2007) et celles qui sont présentes dans l'intestin ne se trouvent généralement pas dans d'autres environnements (Ley et al 2008b). En outre, les microorganismes intestinaux sont largement partagés parmi les mammifères (Ley et al 2008a), ce qui renforce l'idée selon laquelle certains concepts sont universellement applicables à tous les êtres humains et aux espèces d'élevage. Chez l'Homme, un noyau métagénomique minimum pour le bon fonctionnement du microbiome et l'ensemble minimal de gènes nécessaires pour qu'une bactérie trouve sa niche dans l'intestin ont été identifiés (Qin et al 2010). En outre, chez les hôtes humains, un nombre réduit d'assemblages microbiens, appelés entérotypes, a été identifié (Arumugam et al 2011). Ces entérotypes sont caractérisés par la prédominance de différentes chaînes trophiques, reflétant les capacités distinctives de l'hôte à extraire l'énergie des aliments, et ce concept peut s'appliquer aux ruminants (Arumugam et al 2011). Il est intéressant de noter que toutes les fonctions microbiennes importantes sont fournies par les bactéries dominantes et Arumugam et al (2011) suggèrent que les biomarqueurs fonctionnels sont plus robustes que les biomarqueurs phylogénétiques dans l'identification des entérotypes associés aux caractéristiques phénotypiques des hôtes. Les voies métaboliques complémentaires fournies par le microbiome influencent le phénotype des animaux et des humains et les font réagir différemment à l'alimentation et aux médicaments (Nicholson et al 2005, Li et al 2008, Claus et al 2011).

Le métabolisme des polyosides complexes et les voies menant à l'élimination de l'hydrogène sont deux caractéristiques essentielles qui ont été identifiées dans les microbiomes intestinaux (Brulc et al 2009, Qin et al 2010, Arumugam et al 2011, Hess et al 2011, Muegge et al 2011). Ces deux activités sont liées étant donné que l'utilisation des polyosides structuraux des plantes ainsi que l'élimination de l'hydrogène sont deux éléments importants pour l'utilisation efficace des ressources alimentaires fourragères et l'optimisation de la fermentation dans les conditions anaérobies du rumen (Wolin et al 1997). En outre, l'hydrogène est l'élément central qui influence la production de méthane entérique (Janssen 2010).

\section{1 / Comprendre les processus microbiens}

Les interactions entre les gènes et les fonctions présentes dans le catalogue doivent être interprétées, et des approches complémentaires doivent être utilisées pour répondre à des questions fondamentales portant sur l'écologie microbienne du rumen. Quelques exemples de sujets requérant des informations supplémentaires sont exposés ci-dessous. Ces informations seront utiles pour moduler les capacités du microbiome et améliorer la production des ruminants.

Les répercussions du microbiome sur le phénotype du super-organisme s'appliquent à différents niveaux, de la population microbienne unique à la communauté microbienne et aux interactions microbiennes sur l'hôte. L'environnement gastro-intestinal change en permanence (régime alimentaire, consommation d'aliments et d'eau, action péristaltique...), et les symbiotes s'adaptent constamment pour être en parfaite adéquation (Dethlefsen et al 2007). Des variants de la même espèce peuvent résulter de mutations ou de l'acquisition de matériel génétique par Transfert Horizontal de Gènes (THG).
Ces variants occupent différentes niches trophiques et peuvent coexister (Rosenzweig et al 1994). Chez les humains produisant du méthane, on trouve une seule espèce méthanogène dominante, Methanobrevibacter smithii (Eckburg et al 2005). Un microorganisme seul pour une fonction unique pourrait être considéré comme simple. Cependant, il existe une grande diversité de souches de $S$. smithii, qui diffèrent par l'utilisation du formiate et la présence de protéines de type adhésines, ce qui, théoriquement, permettrait à ces variants d'interagir avec différentes bactéries et d'occuper des niches différentes (Hansen et al 2011). Compte tenu de la complexité et de la pression de sélection qui prévaut dans le rumen, il ne fait aucun doute que plusieurs écotypes de méthanogènes, de microorganismes fibrolytiques ou autres co-existent et jouent un rôle fonctionnel dans le microbiome.

Le microbiome du rumen est riche en interactions microbiennes entre ses membres, comme la coopération métabolique, la synergie, la compétition, la prédation, la signalisation cellule-cellule et l'organisation structurelle telle que les biofilms (Hobson et Stewart 1997, Erickson et al 2002). L'information génomique, les outils bioinformatiques pour l'attribution phylogénétique des séquences (Weber et al 2011) et l'application de techniques pouvant fournir des informations sur les interactions directes entre les microorganismes dans l'environnement, telles que le FISH ( Fluorescence In Situ Hybridization ») et le séquençage de cellule unique, fourniront des indications précieuses sur l'écosystème.

Un des agents fondamentaux de changement et d'adaptation dans les communautés microbiennes sont les phages (Clokie et al 2011). En effet, dans les métagénomes intestinaux, les séquences virales sont importantes et représentent près de $6 \%$ des séquences totales trouvées dans le microbiome humain (Arumugam et al 2011). En outre, ce sont des vecteurs de THG, les génomes et métagénomes bactériens intestinaux en contenant de nombreuses preuves. Le rumen n'est pas une exception, des séquences de bactériophages ayant été décrites (Klieve et Bauchop 1988, Dinsdale et al 2008). Le virome est un agent fondamental dans la dynamique du microbiome et il ne doit pas être négligé lors de l'étude des communautés complexes (Rohwer et Youle 2011).

\section{6 / Les perspectives d'avenir}

Il ressort clairement de ce qui précède qu'un catalogue des gènes microbiens du rumen et l'attribution de fonctions à ces gènes est nécessaire pour relier le 
microbiome du rumen aux pratiques nutritionnelles et productives chez les ruminants. Une initiative au sein de la communauté microbiologique du rumen, semblable au projet portant sur le microbiome humain (Turnbaugh et al 2007), est nécessaire afin de produire un ensemble de référence de génomes microbiens du rumen qui soutienne l'analyse et la compréhension des grands ensembles de données métagénomiques. Il serait également utile de formuler des hypothèses à tester pour orienter les expérimentations et conduire ainsi à une meilleure compréhension de la biologie du rumen. Ceci serait possible à travers le séquen- çage des génomes des bactéries du rumen cultivées disponibles et des archées méthanogènes (environ 1000 cultures), ainsi qu'avec des cultures représentatives de champignons et protozoaires anaérobies du rumen. Considérant une taille moyenne de génome bactérien et archéen d'environ 3,5 Mpb et 2,5 Mpb, respectivement, et une couverture de séquençage d'environ 100', nous avons estimé que 300-400 Gpb de séquençage Illumina seraient nécessaires pour atteindre cet objectif. L'objectif initial pourrait être focalisé sur les bactéries et archées cultivables, mais de nouvelles technologies de séquençage génomique de cellule unique pourraient permettre de séquencer des cellules individuelles d'organismes non cultivés si l'analyse des données métagénomiques disponibles montrent invariablement que les taxons considérés comme importants dans le rumen ne sont pas liés à des représentants cultivés. Il s'agit là d'un projet vaste qui exige un financement important, ainsi qu'une coordination et une planification considérables, mais qui améliorerait de façon inestimable la compréhension des quantités de plus en plus importantes de données métagénomiques qui sont générées à partir du rumen.

\section{Références}

Achenbach L.A., Coates J.D., 2000 Disparity between bacterial phylogeny and physiology - comparing 16S rRNA sequences to assess relationships can be a powerful tool, but its limitations need to be considered. ASM News, 66, 714-715.

Acinas S.G., Marcelino L.A., Klepac-Ceraj V., Polz M.F., 2004. Divergence and Redundancy of 16S rRNA Sequences in Genomes with Multiple rrn Operons. J. Bacteriol., 186, 26292635 .

Arumugam M., Raes J., Pelletier E., Le Paslier D., Yamada T., Mende D.R., Fernandes G.R., Tap J., Bruls T., Batto J.M., Bertalan M., Borruel N., Casellas F., Fernandez L., Gautier L., Hansen T., Hattori M., Hayashi T., Kleerebezem M., Kurokawa K., Leclerc M., Levenez F., Manichanh C., Nielsen H.B., Nielsen T., Pons N., Poulain J., Qin J., Sicheritz-Ponten T., Tims S., Torrents D., Ugarte E., Zoetendal E.G., Wang J., Guarner F., Pedersen O., de Vos W.M., Brunak S., Dore J., Weissenbach J., Ehrlich S.D., Bork P., 2011. Enterotypes of the human gut microbiome. Nature. 473, 174-180.

Attwood G.T., Cookson A.C., Kelly W.J., 2004. Genome sequencing of Clostridium proteoclasticum. Reprod. Nutr. Dev., 44 (Suppl. 1), S20.

Attwood G.T., Kelly W.J., Altermann E.H., Leahy S.C., 2008. Analysis of the Methanobrevibacter ruminantium draft genome: understanding methanogen biology to inhibit their action in the rumen. Aust. J. Exp.Agric., 48, 83-88.

Baar C., Eppinger M., Raddatz G., Simon J., Lanz C., Klimmek O., Nandakumar R., Gross R., Rosinus A., Keller H., Jagtap P., Linke B., Meyer F., Lederer H., Schuster S.C., 2003. Complete genome sequence and analysis of Wolinella succinogenes. Proc. Nat. Acad. Sci., 100, 11690-11695.

Bayer S., Kunert A., Ballschmiter M., Greiner-Stoeffele T., 2010. Indication for a new lipolytic enzyme family: isolation and characterization of two esterases from a metagenomic library. J. Mol. Microbiol. Biotechnol., 18, 181-187.

Beloqui A., Pita M., Polaina J., MartinezArias A., Golyshina O.V., Zumarraga M., Yakimov M.M., Garcia-Arellano H., Alcalde M., Fernandez V.M., Elborough K., Andreu J.M., Ballesteros A., Plou F.J., Timmis K.N., Ferrer M., Golyshin P.N., 2006. Novel polyphenol oxidase mined from a metagenome expression library of bovine rumen: biochemical properties, structural analysis, and phylogenetic relationships. J. Biol. Chem., 281, $22933-$ 22942.

Benner S.A., Caraco M.D., Thomson J.M., Gaucher E.A., 2002. Planetary biology-paleontological, geological, and molecular histories of life. Science, 296, 864-868.

Bera-Maillet C., Devillard E., Cezette M. Jouany J.P., Forano E., 2005. Xylanases and carboxymethylcellulases of the rumen protozoa Polyplastron multivesiculatum, Eudiplodinium maggii and Entodinium sp. FEMS Microbiol. Lett., 244, 149-156.

Berg Miller M.E., Antonopoulos D.A., Rincon M.T., Band M., Bari A., Akraiko T., Hernandez A., Thimmapuram J., Henrissat B., Coutinho P.M., Borovok I., Jindou S., Lamed R., Flint H.J., Bayer E.A., White B.A., 2009. Diversity and strain specificity of plant cell wall degrading enzymes revealed by the draft genome of Ruminococcus flavefaciens FD-1. PLoS One, 4, e6650.

Brulc J.M., Antonopoulos D.A., Miller M.E., Wilson M.K., Yannarell A.C., Dinsdale E.A., Edwards R.E., Frank E.D., Emerson J.B., Wacklin P., Coutinho P.M., Henrissat B., Nelson K.E., White B.A., 2009. Gene-centric metagenomics of the fiber-adherent bovine rumen microbiome reveals forage specific glycoside hydrolases. Proc. Nat. Acad. Sci., 106, 1948-1953.

Brumm P., Mead D., Boyum J., Drinkwater C., Gowda K., Stevenson D., Weimer P., 2011. Functional annotation of Fibrobacter succinogenes S85 carbohydrate active enzymes. Appl. Biochem. Biotechnol., 163, 649-657.

Callaway T.R., Dowd S.E., Edrington T.S., Anderson R.C., Krueger N., Bauer N., Kononoff P.J., Nisbet D.J., 2010. Evaluation of bacterial diversity in the rumen and feces of cattle fed different levels of dried distillers grains plus solubles using bacterial tag-encoded FLX amplicon pyrosequencing. J. Anim. Sci., 88, 3977-3983.

Chaban B., Hill J.E., 2011. A 'universal' type II chaperonin PCR detection system for the investigation of Archaea in complex microbial communities. ISME J., 6, 430-439.

Chaucheyras-Durand F., Walker N.D., Bach A., 2008. Effects of active dry yeasts on the rumen microbial ecosystem: Past, present and future. Anim. Feed Sci. Technol., 145, 5-26.
Clauss M., Hume I.D., Hummel J., 2010. Evolutionary adaptations of ruminants and their potential relevance for modern production systems. Animal, 4, 979-992.

Claus S.P., Ellero S.L., Berger B., Krause L., Bruttin A., Molina J.r.m., Paris A., Want E.J., de Waziers I., Cloarec O., Richards S.E., Wang Y., Dumas M.E., Ross A., Rezzi S., Kochhar S., Van Bladeren P., Lindon J.C., Holmes E., Nicholson J.K., 2011. Colonization-induced host-gut microbial metabolic interaction. mBio, 2, e00271-00210.

Clauss M., Müller K., Fickel J., Streich W.J., Hatt J.M., Südekum K.H., 2011. Macroecology of the host determines microecology of endobionts: protozoal faunas vary with wild ruminant feeding type and body mass. J. Zool., 283, 169-185.

Clokie M.R.J., Millard A.D., Letarov A.V., Heaphy S., 2011. Phages in nature. Bacteriophage, 1, 31-45.

Crosby L.D., Criddle C.S., 2003. Understanding bias in microbial community analysis techniques due to rrn operon copy number heterogeneity. Biotechniques, 34, 790 794, 796, 798 passim.

Crosby W.L., Collier B., Thomas D.Y., Teather R.M., Erfle J.D., 1984. Cloning and expression in Escherichia coli of cellulase genes from Bacteroides succinogenes. In: $5^{\text {th }}$ Canadian Bioenergy Research and Development Seminar. Hassain S. (Ed). Elsevier Applied Science Publishers Ltd., Barking, England, 573-576.

Denman S.E., Tomkins N.W., McSweeney C.S., 2007. Quantitation and diversity analysis of ruminal methanogenic populations in response to the antimethanogenic compound bromochloromethane. FEMS Microbiol. Ecol., 62, 313322.

Dethlefsen L., McFall-Ngai M., Relman D.A., 2007. An ecological and evolutionary perspective on human-microbe mutualism and disease. Nature, 449, 811-818.

Devillard E., Goodheart D.B., Karnati S.K.R., Bayer E.A., Lamed R., Miron J., Nelson K.E., Morrison M., 2004. Ruminococcus albus 8 mutants defective in cellulose degradation are deficient in two processive endocellulases, cel48a and cel9b, both of which possess a novel modular architecture. J. Bacteriol., 186, 136-145. 
Diamond J., 2002. Evolution, consequences and future of plant and animal domestication. Nature, 418, 700-707.

Dinsdale E.A., Edwards R.A., Hall D., Angly F., Breitbart M., Brulc J.M., Furlan M., Desnues C., Haynes M., Li L., McDaniel L., Moran M.A., Nelson K.E., Nilsson C., Olson R., Paul J., Brito B.R., Ruan Y., Swan B.K., Stevens R., Valentine D.L., Thurber R.V., Wegley L., White B.A., Rohwer F., 2008. Functional metagenomic profiling of nine biomes. Nature, 452, 629-632.

Doi R.H., Kosugi A., 2004. Cellulosomes: Plant-cell-wall-degrading enzyme complexes. Nature Rev. Microbiol., 2, 541-551.

Dunne J.C., Li D., Kelly W.J., Leahy S.C. Bond J.J., Jordan T.W., Attwood G.T., 2007. Proteins involved in plant polysaccharide depolymerisation are differentially expressed in the Clostridium proteoclasticum secretome. In: Proc. Human Proteome Organisation $6^{\text {th }}$ Ann. World Congr. "Proteomics: From Technology Development of Biomarker Applications", 6-10 October 2007, Molecular and Cellular Proteomics. Bradshaw R., Berligame A.L. (Eds). Am. Soc. Biochem. Mol. Biol., Seoul, Korea.

Durso L.M., Harhay G.P., Smith T.P., Bono J.L., Desantis T.Z., Harhay D.M., Andersen G.L., Keen J.E., Laegreid W.W., Clawson M.L., 2010. Animal-to-animal variation in fecal microbial diversity among beef cattle. Appl. Environ. Microbiol., 76, 4858-4862.

Eckburg P.B., Bik E.M., Bernstein C.N., Purdom E., Dethlefsen L., Sargent M., Gill S.R., Nelson K.E., Relman D.A., 2005. Diversity of the human intestinal microbial flora. Science, 308, 1635-1638.

Edwards J.E., McEwan N.R., Travis A.J., Wallace R.J., 2004. 16S rDNA library-based analysis of ruminal bacterial diversity. Antonie van Leeuwenhoek, 86, 263-281.

Egert M., de Graaf A.A., Smidt H., de Vos W.M., Venema K., 2006. Beyond diversity: functional microbiomics of the human colon. Trends in Microbiol., 14, 86-91.

Erickson D.L., Nsereko V.L., Morgavi D.P., Selinger L.B., Rode L.M., Beauchemin K.A., 2002. Evidence of quorum sensing in the rumen ecosystem: detection of $\mathrm{N}$-acyl homoserine lactone autoinducers in ruminal contents. Can. J. Microbiol., 48, 374-378.

FAO, 2006. World agriculture: towards 2030/2050. Interim Report. Food and Agriculture Organization of the United Nations, Global Perspective Studies Unit, Rome, Italy.

FAO, 2009. United Nations Food and Agriculture Organization, http://faostat.fao.org

Ferrer M., Golyshina O.V., Chernikova T.N., Khachane A.N., Reyes-Duarte D., Santos V.A.P.M.D., Strompl C., Elborough K., Jarvis G., Neef A., Yakimov M.M., Timmis K.N., Golyshin P.N., 2005. Novel hydrolase diversity retrieved from a metagenome library of bovine rumen microflora. Environ.1 Microbiol., 7, 19962010 .

Flint H.J., Bayer E.A., Rincon M.T., Lamed R., White B.A., 2008. Polysaccharide utilization by gut bacteria: potential for new insights from genomic analysis. Nature Rev. Microbiol., 6, 121-131.

Forsberg C.W., Forano E., Chesson A., 2000. Microbial adherence to plant cell wall and enzymatic hydrolysis. In: Ruminant Physiology Digestion Metabolism, growth and reproduc- tion. Cronje P.B. (Ed). CABI Publishing, Wallingford, UK, 79-98.

Fricke W.F., Seedorf H., Henne A., Kruer M., Liesegang H., Hedderich R., Gottschalk G., Thauer R.K., 2006. The genome sequence of Methanosphaera stadtmanae reveals why this human intestinal archaeon is restricted to methanol and $\mathrm{H} 2$ for methane formation and ATP synthesis. J. Bacteriol., 188, 642-658.

Gagen E.J., Denman S.E., Padmanabha J., Zadbuke S., Al Jassim R., Morrison M., McSweeney C.S., 2010. Functional gene analysis suggests different acetogen populations in the bovine rumen and tammar wallaby forestomach. Appl. Environ. Microbiol., 76, 7785-7795.

Gill S.R., Pop M., Deboy R.T., Eckburg P.B., Turnbaugh P.J., Samuel B.S., Gordon J.I., Relman D.A., Fraser-Liggett C.M., Nelson K.E., 2006. Metagenomic analysis of the human distal gut microbiome. Science, 312, 1355-1359.

Gomez-Alvarez V., Teal T.K., Schmidt T.M. 2009. Systematic artifacts in metagenomes from complex microbial communities. ISME J., 3, 1314-1317.

Goodacre R., 2007. Metabolomics of a superorganism. J. Nutr., 137, 259S-266.

Grabherr M.G., Haas B.J., Yassour M., Levin J.Z., Thompson D.A., Amit I., Adiconis X., Fan L., Raychowdhury R., Zeng Q., Chen Z., Mauceli E., Hacohen N., Gnirke A., Rhind N., di Palma F., Birren B.W., Nusbaum C., Lindblad-Toh K., Friedman N., Regev A., 2011. Full-length transcriptome assembly from RNA-Seq data without a reference genome. Nature Biotechnol., 29, 644-652.

Griffith G.W., Baker S., Fliegerova K., Liggenstoffer A., van der Giezen M., Voigt K., Beakes G., 2010. Anaerobic fungi: Neocallimastigomycota. IMA Fungus: The Global Mycological J., 1, 181-185.

Groleau D., Forsberg C.W., 1981. Cellulolytic activity of the rumen bacterium Bacteroides succinogenes. Can. J. Microbiol., 27, 517-530.

Guan L.L., Nkrumah J.D., Basarab J.A. Moore S.S., 2008. Linkage of microbial ecology to phenotype: correlation of rumen microbial ecology to cattle's feed efficiency. FEMS Microbiol. Lett., 288, 85-91.

Hansen E.E., Lozupone C.A., Rey F.E., Wu M., Guruge J.L., Narra A., Goodfellow J., Zaneveld J.R., McDonald D.T., Goodrich J.A., Heath A.C., Knight R., Gordon J.I., 2011. Pangenome of the dominant human gut-associated archaeon, Methanobrevibacter smithii, studied in twins. Proc. Nat. Acad. Sci., 108, 4599-4606.

Head I.M., Saunders J.R., Pickup R.W., 1998. Microbial Evolution, Diversity, and Ecology: A Decade of Ribosomal RNA Analysis of Uncultivated Microorganisms. Microb. Ecol., 35, 1-21.

Henderson G., Naylor G.E., Leahy S.C., Janssen P.H., 2010. Presence of novel, potentially homoacetogenic bacteria in the rumen as determined by analysis of formyltetrahydrofolate synthetase sequences from ruminants. Appl. Environ. Microbiol., 76, 2058-2066.

Hess M., Sczyrba A., Egan R., Kim T.W., Chokhawala H., Schroth G., Luo S., Clark D.S., Chen F., Zhang T., Mackie R.I., Pennacchio L.A., Tringe S.G., Visel A., Woyke T., Wang Z., Rubin E.M., 2011. Metagenomic discovery of biomass-degrading genes and genomes from cow rumen. Science, 331, 463-467.
Hobson P.N., Stewart C.S., 1997. The Rumen Microbial Ecosystem. Chapman \& Hall, London, UK, 719p.

Hong S.H., Kim J.S., Lee S.Y., In Y.H., Choi S.S., Rih J.K, Kim C.H., Jeong H., Hur C.G. Kim J.J., 2004. The genome sequence of the capnophilic rumen bacterium Mannheimia succiniciproducens. Nature Biotechnol., 22, 1275-1281.

Hooper L.V., 2004. Bacterial contributions to mammalian gut development. Trends Microbiol., $12,129-134$

Huang H., Zhang R., Fu D., Luo J., Li Z., Luo H., Shi P., Yang P., Diao Q., Yao B., 2010. Diversity, abundance and characterization of ruminal cysteine phytases suggest their important role in phytate degradation. Environ. Microbiol., 13, 747-757.

Hume I.D., Warner A.C.I., 1980. Evolution of microbial digestion in mammals. In: Digestive physiology and metabolism in ruminants. Ruckebusch Y., Thivend P. (Eds). MTP Press, Lancaster, UK, 665-684.

Huws S.A., Edwards J.E., Kim E.J., Scollan N.D., 2007. Specificity and sensitivity of eubacterial primers utilized for molecular profiling of bacteria within complex microbial ecosystems. J. Microbiol. Meth., 70, 565-569.

Janssen P.H., 2010. Influence of hydrogen on rumen methane formation and fermentation balances through microbial growth kinetics and fermentation thermodynamics. Anim. Feed Sci. Technol., 160, 1-22.

Janssen P.H., Kirs M., 2008. Structure of the archaeal community of the rumen. Appl. Environ. Microbiol., 74, 3619-3625.

Jouany J.P., Morgavi D.P., 2007. Use of 'natural' products as alternatives to antibiotic feed additives in ruminant production. Animal, 1, 1443-1466.

Jun H.S., Qi M., Ha J.K., Forsberg C.W., 2007. Fibrobacter succinogenes, a dominant fibrolytic ruminal bacterium: Transition to the post genomic era. Asian-Australasian J. Anim.Sci., 20, 802-810.

Kanagawa T., 2003. Bias and artifacts in multitemplate polymerase chain reactions (PCR). J. Biosci. Bioengin., 96, 317-323.

Kandler O., König H., 1978. Chemical composition of the peptidoglycan-free cell walls of methanogenic bacteria. Arch. Microbiol., 118, 141-152.

Kandler O., König H., 1985. Cell envelopes of archaebacteria. In: The bacteria. Woese C.R., Wolfe R.S. (Eds). Academic Press, Inc., New York, USA, 413-457.

Karlsson F.H., Nookaew I., Petranovic D., Nielsen J., 2011. Prospects for systems biology and modeling of the gut microbiome. TIBTECH, $29,251-258$.

Kelly W.J., Leahy S.C., Altermann E., Yeoman C.J., Dunne J.C., Kong Z., Pacheco D.M., Li D., Noel S.J., Moon C.D., Cookson A.L., Attwood G.T., 2010. The glycobiome of the rumen bacterium Butyrivibrio Proteoclasticus $\mathrm{B} 316^{\mathrm{T}}$ highlights adaptation to a polysaccharide-rich environment. PLoS One, $5, \mathrm{e} 11942$.

Kenters N., Henderson G., Jeyanathan J., Kittelmann S., Janssen P.H., 2010. Isolation of previously uncultured rumen bacteria by dilution to extinction using a new liquid culture medium. J. Microbiol. Meth., 84, 52-60.

Khafipour E., Li S., Plaizier J.C., Krause D.O., 2009. Rumen microbiome composition 
determined using two nutritional models of subacute ruminal acidosis. Appl. Environ. Microbiol., 75, 7115-7124.

Kim M., Morrison M., Yu Z., 2011. Status of the phylogenetic diversity census of ruminal microbiomes. FEMS Microbiol. Ecol., 76, 49-63.

Kittelmann S., Janssen P.H., 2011. Characterization of rumen ciliate community composition in domestic sheep, deer, and cattle, feeding on varying diets, by means of PCRDGGE and clone libraries. FEMS Microbiol. Ecol., 75, 468-481.

Kittelmann S., Naylor G.E., Koolaard J.P., Janssen P.H., 2012. A proposed taxonomy of anaerobic fungi (class neocallimastigomycetes) suitable for large-scale sequence-based community structure analysis. PLoS One, 7, e36866.

Klieve A.V., Bauchop T., 1988. Morphological diversity of ruminal bacteriophages from sheep and cattle. Appl. Environ. Microbiol., 54, 1637-1641.

Koike S., Handa Y., Goto H., Sakai K., Miyagawa E., Matsui H., Ito S., Kobayashi Y., 2010. Molecular Monitoring and Isolation of Previously Uncultured Bacterial Strains from the Sheep Rumen. Appl. Environ. Microbiol., 76, 1887-1894.

Konopka A., 2009. What is microbial community ecology? ISME J., 3, 1223-1230.

Kudo H., Cheng K.J., Costerton J.W., 1987. Electron microscopic study of the methylcellulose-mediated detachment of cellulolytic rumen bacteria from cellulose fibers. Can. J. Microbiol., $32,244-248$

Larue R., Yu Z., Parisi V.A., Egan A.R., Morrison M., 2005. Novel microbial diversity adherent to plant biomass in the herbivore gastrointestinal tract, as revealed by ribosomal intergenic spacer analysis and rrs gene sequencing. Environ. Microbiol., 7, 530-543.

Leahy S.C., Kelly W.J., Altermann E., Ronimus R.S., Yeoman C.J., Pacheco D.M., Li D., Kong Z., McTavish S., Sang C., Lambie S.C., Janssen P.H., Dey D., Attwood G.T., 2010. The genome sequence of the rumen methanogen Methanobrevibacter ruminantium reveals new possibilities for controlling ruminant methane emissions. PLoS One, 5, e8926.

Lederberg J., 2000. Infectious History. Science, 288, 287-293.

Ley R.E., Hamady M., Lozupone C., Turnbaugh P.J., Ramey R.R., Bircher J.S., Schlegel M.L., Tucker T.A., Schrenzel M.D., Knight R., Gordon J.I., 2008a. Evolution of mammals and their gut microbes. Science, 320 1647-1651.

Ley R.E., Lozupone C.A., Hamady M., Knight R., Gordon J.I., 2008b. Worlds within worlds: evolution of the vertebrate gut microbiota. Nature Rev. Microbiol., 6, 776-788.

Li M., Wang B., Zhang M., Rantalainen M., Wang S., Zhou H., Zhang Y., Shen J., Pang X., Zhang M., Wei H., Chen Y., Lu H., Zuo J., Su M., Qiu Y., Jia W., Xiao C., Smith L.M., Yang S., Holmes E., Tang H., Zhao G., Nicholson J.K., Li L., Zhao L., 2008. Symbiotic gut microbes modulate human metabolic phenotypes. Proc. Nat. Acad. Sci., 105, 2117-2122.

Liu Y., Whitman W.B., 2008. Metabolic, phylogenetic, and ecological diversity of the methanogenic Archaea. Ann. N.Y. Acad. Sci., 1125, 171-189.

Liu K., Wang J., Bu D., Zhao S., McSweeney C., Yu P., Li D., 2009. Isolation and biochemical characterization of two lipases from a metagenomic library of China Holstein cow rumen. Biochem. Biophys. Res. Commun, $385,605-611$.

Luo H.W., Zhang H., Suzuki T., Hattori S., Kamagata Y., 2002. Differential expression of methanogenesis genes of Methanothermobacter thermoautotrophicus (formerly Methanobacterium thermoautotrophicum) in pure culture and in cocultures with fatty acid-oxidizing syntrophs. Appl. Environ. Microbiol., 68, 1173-1179.

Luton P.E., Wayne J.M., Sharp R.J., Riley P.W., 2002. The mcrA gene as an alternative to $16 \mathrm{~S}$ rRNA in the phylogenetic analysis of methanogen populations in landfill. Microbiology, 148, 3521-3530.

Lynd L.R., Weimer P.J., van Zyl W.H., Pretorius I.S., 2002. Microbial cellulose utilization: Fundamentals and biotechnology. Microbiol. Mol. Biol. Rev., 66, 506-577.

Mackie R.I., McSweeney C.S., Klieve A.V., 2002. Microbial ecology of the ovine rumen. In: Sheep Nutrition. Freer M., Dove H. (Eds) CABI Publishing, Wallingford, UK, 71-94.

Martin C., Morgavi D.P., Doreau M., 2010. Methane mitigation in ruminants: from microbe to the farm scale. Animal, 4, 351-365.

Marx H., Graf A.B., Tatto N.E., Thallinger G.G., Mattanovich D., Sauer M., 2011. Genome sequence of the ruminal bacterium Megasphaera elsdenii. J. Bacteriol., 193, 55785579.

Math R.K., Islam S.M.A., Cho K.M., Hong S.J., Kim J.M., Yun M.G., Cho J.J., Heo J.Y., Lee Y.H., Kim H., Yun H.D., 2010. Isolation of a novel gene encoding a 3,5,6-trichloro-2pyridinol degrading enzyme from a cow rumen metagenomic library. Biodegradation, 21, 565573

Michelland R.J., Monteils V., Zened A., Combes S., Cauquil L., Gidenne T., Hamelin J., Fortun-Lamothe L., 2009. Spatial and temporal variations of the bacterial community in the bovine digestive tract. J. Appl. Microbiol. 107, 1642-1650.

Morgavi D.P., Forano E., Martin C. Newbold C.J., 2010. Microbial ecosystem and methanogenesis in ruminants. Animal, 4, 10241036

Morgavi D.P., Martin C., Jouany J.P., Ranilla M.J., 2012. Rumen protozoa and methanogenesis: not a simple cause-effect relationship. Br. J. Nutr., 107, 388-397.

Morrison M., Pope P.B., Denman S.E., McSweeney C.S., 2009. Plant biomass degradation by gut microbiomes: more of the same or something new? Cur. Opin. Biotechnol., 20, 358-363.

Mosoni P., Martin C., Forano E., Morgavi D.P., 2011. Long-term defaunation increases the abundance of cellulolytic ruminococci and methanogens but does not affect the bacterial and methanogen diversity in the rumen of sheep. J. Anim. Sci., 89, 783-791.

Muegge B.D., Kuczynski J., Knights D., Clemente J.C., Gonzalez A., Fontana L., Henrissat B., Knight R., Gordon J.I., 2011. Diet drives convergence in gut microbiome functions across mammalian phylogeny and within humans. Science, 332, 970-974.

Nagaraja T.G., Newbold C.J., Van Nevel C.J., Demeyer D.I., 1997. Manipulation of ruminal fermentation. In: Rumen microbial ecosystem. Hobson P.N., Stewart C.S. (Eds) Blackie Academic \& Professional, London, UK, 523-632.

Nicholson J.K., Holmes E., Wilson I.D., 2005. Gut microorganisms, mammalian metabolism and personalized health care. Nature Rev. Microbiol., 3, 431-438.

Olivier J., Van Aardenne J., Dentener F., Pagliari V., Ganzeveld L., Peters J., 2005. Recent trends in global greenhouse gas emissions:regional trends 1970-2000 and spatial distribution of key sources in 2000. Environ. Sci., 2, 81-99.

Pedros-Alio C., 2006. Marine microbial diversity: can it be determined? Trends Microbiol., 14, 257-263.

Perkel J., 2011. Making contact with sequencing's fourth generation. Biotechniques, 50, 93-95.

Pitta D., Pinchak W., Dowd S., Osterstock J., Gontcharova V., Youn E., Dorton K., Yoon I., Min B., Fulford J., Wickersham T., Malinowski D., 2010. Rumen bacterial diversity dynamics associated with changing from bermudagrass hay to grazed winter wheat diets. Microb. Ecol., 59, 511-522.

Popova M., Martin C., Eugène M., Mialon M.M., Doreau M., Morgavi D.P., 2011. Effect of fibre- and starch-rich finishing diets on methanogenic Archaea diversity and activity in the rumen of feedlot bulls. Anim. Feed Sci. Technol., 166-167, 113-121.

Pukall R., Lapidus A., Nolan M., Copeland A., Del Rio T.G., Lucas S., Chen F., Tice H., Cheng J.F., Chertkov O., Bruce D., Goodwin L., Kuske C., Brettin T., Detter J.C., Han C., Pitluck S., Pati A., Mavrommatis K., Ivanova N., Ovchinnikova G., Chen A., Palaniappan K., Schneider S., Rohde M., Chain P., D'Haeseleer P., Goker M., Bristow J., Eisen J.A., Markowitz V., Kyrpides N.C., Klenk H.P., Hugenholtz P., 2009. Complete genome sequence of Slackia heliotrinireducens type strain (RHS 1(T)). Standards Genomic Sci., 1, 234-241

Purushe J., Fouts D.E., Morrison M., White B.A., Mackie R.I., Coutinho P.M., Henrissat B., Nelson K.E., 2010. Comparative genome analysis of Prevotella ruminicola and Prevotella bryantii: insights into their environmental niche. Microb. Ecol., 60, 721-729.

Qin J., Li R., Raes J., Arumugam M., Burgdorf K.S., Manichanh C., Nielsen T., Pons N., Levenez F., Yamada T., Mende D.R., Li J., Xu J., Li S., Li D., Cao J., Wang B., Liang H., Zheng H., Xie Y., Tap J., Lepage P., Bertalan M., Batto J.M., Hansen T., Le Paslier D., Linneberg A., Nielsen H.B., Pelletier E., Renault P., Sicheritz-Ponten T., Turner K., Zhu H., Yu C., Li S., Jian M., Zhou Y., Li Y., Zhang X., Li S., Qin N., Yang H., Wang J., Brunak S., Dore J., Guarner F., Kristiansen K., Pedersen O., Parkhill J., Weissenbach J., Bork P., Ehrlich S.D., Wang J., 2010. A human gut microbial gene catalogue established by metagenomic sequencing. Nature, 464, 59-65.

Quince C., Lanzen A., Curtis T.P., Davenport R.J., Hall N., Head I.M., Read L.F., Sloan W.T., 2009. Accurate determination of microbial diversity from 454 pyrosequencing data. Nature Methods, 6, 639-641.

Raes J., Bork P., 2008. Molecular eco-systems biology: towards an understanding of community function. Nature Rev. Microbiol., 6, 693-699.

Reeve J.N., Nolling J., Morgan R.M., Smith D.R., 1997. Methanogenesis: genes, genomes, 
and who's on first? J. Bacteriol., 179, 59755986.

Rincon M.T., Dassa B., Flint H.J., Travis A.J., Jindou S., Borovok I., Lamed R., Bayer E.A., Henrissat B., Coutinho P.M., Antonopoulos D.A., Berg Miller M.E., White B.A., 2010. Abundance and diversity of dockerin-containing proteins in the fiber-degrading rumen bacterium, Ruminococcus flavefaciens FD-1. PLoS One, 5, e12476.

Rohwer F., Youle M., 2011. Consider something viral in your research. Nature Rev. Microbiol., 9, 308-309.

Rosenzweig R.F., Sharp R.R., Treves D.S., Adams J., 1994. Microbial Evolution in a Simple Unstructured Environment: Genetic Differentiation in Escherichia coli. Genetics, 137, 903-917.

Rosselló-Mora R., Amann R., 2001. The species concept for prokaryotes. FEMS Microbiol. Rev., 25, 39-67.

Russell J.B., Muck R.E., Weimer P.J., 2009. Quantitative analysis of cellulose degradation and growth of cellulolytic bacteria in the rumen. FEMS Microbiol. Ecol., 67, 183-197.

Sadet S., Martin C., Meunier B., Morgavi D.P., 2007. PCR-DGGE analysis reveals a distinct diversity in the bacterial population attached to the rumen epithelium. Animal, 1, 939-944.

Samuel B.S., Hansen E.E., Manchester J.K., Coutinho P.M., Henrissat B., Fulton R., Latreille P., Kim K., Wilson R.K., Gordon J.I., 2007. Genomic and metabolic adaptations of Methanobrevibacter smithii to the human gut. Proc. Nat. Acad. Sci., 104, 10643-10648.

Shanks O.C., Kelty C.A., Archibeque S., Jenkins M., Newton R.J., McLellan S.L., Huse S.M., Sogin M.L., 2011. Community Structures of Fecal Bacteria in Cattle from Different Animal Feeding Operations. Appl. Environ. Microbiol., 77, 2992-3001.

Simon C., Daniel R., 2011. Metagenomic analyses: past and future trends. Appl. Environ. Microbiol, 77, 1153-1161.

Stevens C.E., Hume I.D., 1998. Contributions of microbes in vertebrate gastrointestinal tract to production and conservation of nutrients. Physiol. Rev., 78, 393-427.

Stevenson D.M., Weimer P.J., 2007. Dominance of Prevotella and low abundance of classical ruminal bacterial species in the bovine rumen revealed by relative quantification real-time PCR. Appl. Microbiol. Biotechnol., $75,165-174$

Suen G., Weimer P.J., Stevenson D.M., Aylward F.O., Boyum J., Deneke J., Drinkwater C., Ivanova N.N., Mikhailova N., Chertkov O., Goodwin L.A., Currie C.R., Mead D., Brumm P.J., 2011. The complete genome sequence of Fibrobacter succinogenes S85 reveals a cellulolytic and metabolic specialist. PLoS One, 6.

Sundset M., Edwards J., Cheng Y., Senosiain R., Fraile M., Northwood K., Præsteng K., Glad T., Mathiesen S., Wright A.D., 2009. Molecular diversity of the rumen microbiome of norwegian reindeer on natural summer pasture. Microb. Ecol., 57, 335-348.

Teather R.M., 2001. Community genomics The key to the rumen? In: Advances in Beef Cattle Science. Beauchemin K.A., Crews D.H.J. (Eds). Livestock Sciences Section, Lethbridge Research Centre, Agriculture and
Agri-Food Canada (AAFC), Lethbridge, Canada, 228-233.

The Bovine Genome Sequencing Analysis Consortium, Elsik C.G., Tellam R.L., Worley K.C., Gibbs R.A., Muzny D.M., Weinstock G.M., Adelson D.L., Eichler E.E., Elnitski L., Guigo R., Hamernik D.L., Kappes S.M., Lewin H.A., Lynn D.J., Nicholas F.W., Reymond A. Rijnkels M., Skow L.C., Zdobnov E.M., Schook L., Womack J., Alioto T., Antonarakis S.E., Astashyn A., Chapple C.E., Chen H.C., Chrast J., Camara F., Ermolaeva O., Henrichsen C.N., Hlavina W., Kapustin Y., Kiryutin B., Kitts P., Kokocinski F., Landrum M., Maglott D., Pruitt K., Sapojnikov V., Searle S.M., Solovyev V., Souvorov A., Ucla C., Wyss C., Anzola J.M., Gerlach D., Elhaik E., Graur D., Reese J.T., Edgar R.C., McEwan J.C., Payne G.M., Raison J.M., Junier T., Kriventseva E.V., Eyras E., Plass M., Donthu R., Larkin D.M., Reecy J., Yang M.Q., Chen L., Cheng Z., Chitko-McKown C.G., Liu G.E., Matukumalli L.K., Song J., Zhu B., Bradley D.G., Brinkman F.S.L., Lau L.P.L. Whiteside M.D., Walker A., Wheeler T.T., Casey T., German J.B., Lemay D.G., Maqbool N.J., Molenaar A.J., Seo S., Stothard P., Baldwin C.L., Baxter R., Brinkmeyer-Langford C.L., Brown W.C., Childers C.P., Connelley T., Ellis S.A., Fritz K., Glass E.J., Herzig C.T.A., Iivanainen A., Lahmers K.K., Bennett A.K., Dickens C.M., Gilbert J.G.R., Hagen D.E., Salih H., Aerts J., Caetano A.R., Dalrymple B., Garcia J.F., Gill C.A., Hiendleder S.G., Memili E., Spurlock D., Williams J.L., Alexander L., Brownstein M.J., Guan L., Holt R.A., Jones S.J.M., Marra M.A., Moore R., Moore S.S., Roberts A., Taniguchi M., Waterman R.C., Chacko J., Chandrabose M.M., Cree A., Dao M.D., Dinh H.H., Gabisi R.A., Hines S., Hume J., Jhangiani S.N., Joshi V., Kovar C.L., Lewis L.R., Liu Y.-S., Lopez J., Morgan M.B., Nguyen N.B., Okwuonu G.O., Ruiz S.J., Santibanez J., Wright R.A., Buhay C., Ding Y., Dugan-Rocha S., Herdandez J., Holder M., Sabo A., Egan A., Goodell J., Wilczek-Boney K., Fowler G.R., Hitchens M.E., Lozado R.J., Moen C., Steffen D., Warren J.T., Zhang J., Chiu R., Schein J.E., Durbin K.J., Havlak P., Jiang H. Liu Y., Qin X., Ren Y., Shen Y., Song H., Bell S.N., Davis C., Johnson A.J., Lee S., Nazareth L.V., Patel B.M., Pu L.L., Vattathil S., Williams R.L., Jr., Curry S., Hamilton C., Sodergren E., Wheeler D.A., Barris W., Bennett G.L., Eggen A., Green R.D., Harhay G.P., Hobbs M., Jann O., Keele J.W., Kent M.P., Lien S., McKay S.D., McWilliam S., Ratnakumar A., Schnabel R.D., Smith T., Snelling W.M., Sonstegard T.S., Stone R.T., Sugimoto Y., Takasuga A., Taylor J.F., Van Tassell C.P., MacNeil M.D., Abatepaulo A.R.R., Abbey C.A., Ahola V., Almeida I.G., Amadio A.F., Anatriello E., Bahadue S.M., Biase F.H., Boldt C.R., Carroll J.A., Carvalho W.A., Cervelatti E.P., Chacko E., Chapin J.E., Cheng Y., Choi J., Colley A.J., de Campos T.A., De Donato M., Santos I.K.F.d.M., de Oliveira C.J.F., Deobald H., Devinoy E., Donohue K.E., Dovc P., Eberlein A., Fitzsimmons C.J., Franzin A.M., Garcia G.R., Genini S., Gladney C.J., Grant J.R., Greaser M.L., Green J.A., Hadsell D.L., Hakimov H.A., Halgren R., Harrow J.L., Hart E.A., Hastings N., Hernandez M., Hu Z.L., Ingham A., Iso-Touru T., Jamis C., Jensen K., Kapetis D., Kerr T., Khalil S.S., Khatib H., Kolbehdari D., Kumar C.G., Kumar D., Leach R., Lee J.C.M., Li C., Logan K.M., Malinverni R., Marques E., Martin W.F., Martins N.F., Maruyama S.R., Mazza R., McLean K.L., Medrano J.F., Moreno B.T., More D.D., Muntean C.T., Nandakumar H.P., Nogueira M.F.G., Olsaker I., Pant S.D., Panzitta F., Pastor R.C.P., Poli M.A., Poslusny N., Rachagani S., Ranganathan S., Razpet A., Riggs P.K., Rincon G., Rodriguez-Osorio N., Rodriguez-Zas S.L., Romero N.E., Rosenwald A., Sando L., Schmutz S.M., Shen L., Sherman L., Southey B.R.,
Lutzow Y.S., Sweedler J.V., Tammen I., Telugu B.P.V.L., Urbanski J.M., Utsunomiya Y.T., Verschoor C.P., Waardenberg A.J., Wang Z., Ward R., Weikard R., Welsh T.H., Jr., White S.N., Wilming L.G., Wunderlich K.R., Yang J., Zhao F.-Q., 2009. The genome sequence of taurine cattle: A window to ruminant biology and evolution. Science, 324, 522-528.

The Human Microbiome Jumpstart Reference Strains C., 2010. A catalog of reference genomes from the human microbiome. Science, 328, 994-999.

The International Sheep Genomics Consortium, Archibald A.L., Cockett N.E., Dalrymple B.P., Faraut T., Kijas J.W., Maddox J.F., McEwan J.C., Hutton Oddy V., Raadsma H.W., Wade C., Wang J., Wang W., Xun X., 2010. The sheep genome reference sequence: a work in progress. Anim. Gen., 41, 449-453.

Turnbaugh P.J., Ley R.E., Hamady M., Fraser-Liggett C.M., Knight R., Gordon J.I., 2007. The human microbiome project. Nature, 449, 804-810.

von Mering C., Hugenholtz P., Raes J., Tringe S.G., Doerks T., Jensen L.J., Ward N., Bork P., 2007. Quantitative phylogenetic assessment of microbial communities in diverse environments. Science, 315, 11261130 .

Wallace R.J., 2008. Gut microbiology broad genetic diversity, yet specific metabolic niches. Animal, 2, 661-668.

Wang F.C., Li F., Chen G.J., Liu W.F., 2009. Isolation and characterization of novel cellulase genes from uncultured microorganisms in different environmental niches. Microbiol. Res., 164, 650-657.

Weber M., Teeling H., Huang S., Waldmann J., Kassabgy M., Fuchs B.M., Klindworth A., Klockow C., Wichels A., Gerdts G., Amann R., Glockner F.O., 2011. Practical application of self-organizing maps to interrelate biodiversity and functional data in NGS-based metagenomics. ISME J., 5, 918-928.

Weimer P.J., 1998. Manipulating ruminal fermentation: a microbial ecological perspective. J. Anim. Sci., 76, 3114-3122.

Weimer P.J., Odt C.L., 1995. Cellulose degradation by ruminal microbes: Physiological and hydrolytic diversity among ruminal cellulolytic bacteria. In: Enzymatic Degradation of Insoluble Carbohydrates. Saddler J., Penner M. (Eds). American Chemical Society, Washington, DC, 291-304.

Weimer P.J., Russell J.B., Muck R.E., 2009. Lessons from the cow: What the ruminant animal can teach us about consolidated bioprocessing of cellulosic biomass. Bioresour. Technol., 100, 5323-5331.

Welkie D.G., Stevenson D.M., Weimer P.J., 2010. ARISA analysis of ruminal bacterial community dynamics in lactating dairy cows during the feeding cycle. Anaerobe, 16, 94-100.

Whitford M.F., Forster R.J., Beard C.E., Gong J., Teather R.M., 1998. Phylogenetic analysis of rumen bacteria by comparative sequence analysis of cloned 16S rRNA genes. Anaerobe, 4, 153-163.

Williams A.G., Coleman G.S., 1992. The rumen protozoa. Springer-Verlag New York Inc., New York, USA, 441p.

Wilson D.B., 2011. Microbial diversity of cellulose hydrolysis. Cur. Opin. Microbiol., 14, 259-263. 
Wolin M., Miller T., Stewart C., 1997. Microbe-microbe interactions. In: The Rumen Microbial Ecosystem. Hobson P., Stewart C. (Eds). Chapman \& Hall, London, UK, 467-491.

Wong D., Chan V.J., McCormack A.A., Batt S.B., 2010a. Cloning and characterization of an exo-xylogucanase from rumenal microbial metagenome. Protein and Peptide Letters, 17, 803-808.

Wong D., Chan V.J., McCormack A.A., Batt S.B., 2010b. A novel xyloglucan-specific endob-1,4-glucanase: biochemical properties and inhibition studies. Appl. Microbiol. Biotechnol., 86, 1463-1471.

Wong D.W.S., Chan V.J., Batt S.B., 2008. Cloning and characterization of a novel exo-a-
1,5-L-arabinanase gene and the enzyme. Appl. Microbiol. Biotechnol., 79, 941-949.

Wong D.W.S., Chan V.J., McCormack A.A., 2009. Functional cloning and expression of a novel endo- $\alpha-1,5$-L-arabinanase from a metagenomic library. Protein and Peptide Letters, 16 1435-1441.

World Bank, 2008. Rising food and fuel prices: addressing the risks to future generations. http://siteresources.worldbank.org/DEVCOMMEXT/Resources/Food-Fuel.pdf. consulté le September 2009, available at http://siteresources.worldbank.org/DEVCOMMEXT/Reso urces/Food-Fuel.pdf

Xu J., Gordon J.I., 2003. Inaugural Article: Honor thy symbionts. Proc. Nat. Acad. Sci. 100, 10452-10459.
Yáñez-Ruiz D.R., Hart K.J., Martin-Garcia A.I., Ramos S., Newbold C.J., 2008. Diet composition at weaning affects the rumen microbial population and methane emissions by lambs. Aust. J. Exp. Agric., 48, 186-188.

Yáñez-Ruiz D.R., Macías B., Pinloche E., Newbold C.J., 2010. The persistence of bacterial and methanogenic archaeal communities residing in the rumen of young lambs. FEMS Microbiol. Ecol., 72, 272-278.

Zhou M., Hernandez-Sanabria E., Guan L.L., 2010. Characterization of variation in rumen methanogenic communities under different dietary and host feed efficiency conditions, as determined by PCR-denaturing gradient gel electrophoresis analysis. Appl. Environ. Microbiol., 76, 3776-3786

\section{Résumé}

La viande et le lait produits par les ruminants sont d'importants produits agricoles qui représentent une source importante de protéines pour les humains. La production des ruminants a une valeur économique considérable et un impact sur la sécurité alimentaire de nombreuses régions du monde. Cependant, le secteur fait face à des défis majeurs en raison de la diminution des ressources naturelles et de la conséquente hausse des prix, mais également en raison de la prise de conscience grandissante de l'empreinte écologique laissée par les ruminants d'élevage. Une particularité des ruminants est la digestion prégastrique des aliments par les microbes du rumen. Une meilleure connaissance du microbiome du rumen et de ses fonctions aura pour conséquence une amélioration de l'efficacité de la digestion des aliments et une réduction de la production de méthane entérique, contribuant ainsi à relever les défis de la durabilité. Le progrès des technologies de séquençage d'ADN et de la bioinformatique accroît notre connaissance des écosystèmes microbiens complexes, y compris du tractus gastro-intestinal des mammifères. L'application de ces techniques à l'écosystème du rumen a permis d'étudier la diversité microbienne sous différentes conditions alimentaires et de production. Par ailleurs, le séquençage des génomes de différentes espèces bactériennes et d'archées isolées du rumen fournit des informations détaillées sur leur physiologie. La métagénomique, utilisée principalement pour comprendre les mécanismes enzymatiques impliqués dans la dégradation des polyosides structurels des végétaux, commence à offrir de nouvelles connaissances en permettant de contourner les limitations imposées par la culture des espèces microbiennes et ainsi de permettre l'accès à la totalité de la communauté. Ces approches permettent non seulement de caractériser la structure de la communauté microbienne du rumen, mais aussi d'établir un lien entre celle-ci et les fonctions du microbiome du rumen. Les premiers résultats obtenus grâce à ces technologies à haut débit ont également montré que le microbiome du rumen est bien plus complexe et diversifié que le caecum humain. Par conséquent, le catalogage de ses gènes exigera des efforts de séquençage et bioinformatiques considérables, mais constitue néanmoins un objectif réaliste. Un catalogue des gènes microbiens du rumen est nécessaire pour comprendre la fonction du microbiome et son interaction avec l'animal hôte et ses aliments. De plus, il fournira une base pour les modèles d'intégration microbiome-hôte et bénéficiera aux stratégies cherchant à diminuer l'action polluantes des ruminants et à les rendre plus robustes et rentables.

\section{Abstract}

\section{Rumen microbial (meta)genomics and its application to ruminant production}

Meat and milk produced by ruminants are important agricultural products and are major sources of protein for humans. Ruminant production is of considerable economic value and underpins food security in many regions of the world. However, the sector faces major challenges because of diminishing natural resources, ensuing increases in production costs, and also because of the increased awareness of the environmental impact of ruminant farming. The digestion of feed and the production of enteric methane are key functions that could be manipulated thorough a understanding of the rumen microbiome. Advances in DNA sequencing technologies and bioinformatics are transforming our understanding of complex microbial ecosystems, including the gastrointestinal tract of mammals. The application of these techniques to the rumen ecosystem has allowed the study of microbial diversity under different dietary and production conditions. Furthermore, the sequencing of genomes from several cultured rumen bacterial and archaeal species is providing detailed information about their physiology. More recently, metagenomics, mainly aimed at understanding the enzymatic machinery involved in the degradation of plant structural polyosides, is starting to produce new insights by allowing access to the total community and sidestepping the limitations imposed by cultivation. These advances highlight the promise of these approaches for characterising the rumen microbial community structure and linking this with the functions of the rumen microbiota. Initial results using high-throughput culture independent technologies have also shown that the rumen microbiome is far more complex and diverse than the human caecum. Therefore, cataloguing its genes will require a considerable sequencing and bioinformatic effort. Nevertheless, the construction of a rumen microbial gene catalogue through metagenomics and genomic sequencing of key populations is an attainable goal. A rumen microbial gene catalogue is necessary to understand the function of the microbiome and its interaction with the host animal and feeds, and it will provide a basis for integrative microbiome-host models and inform strategies promoting less-polluting, more robust and efficient ruminants. 